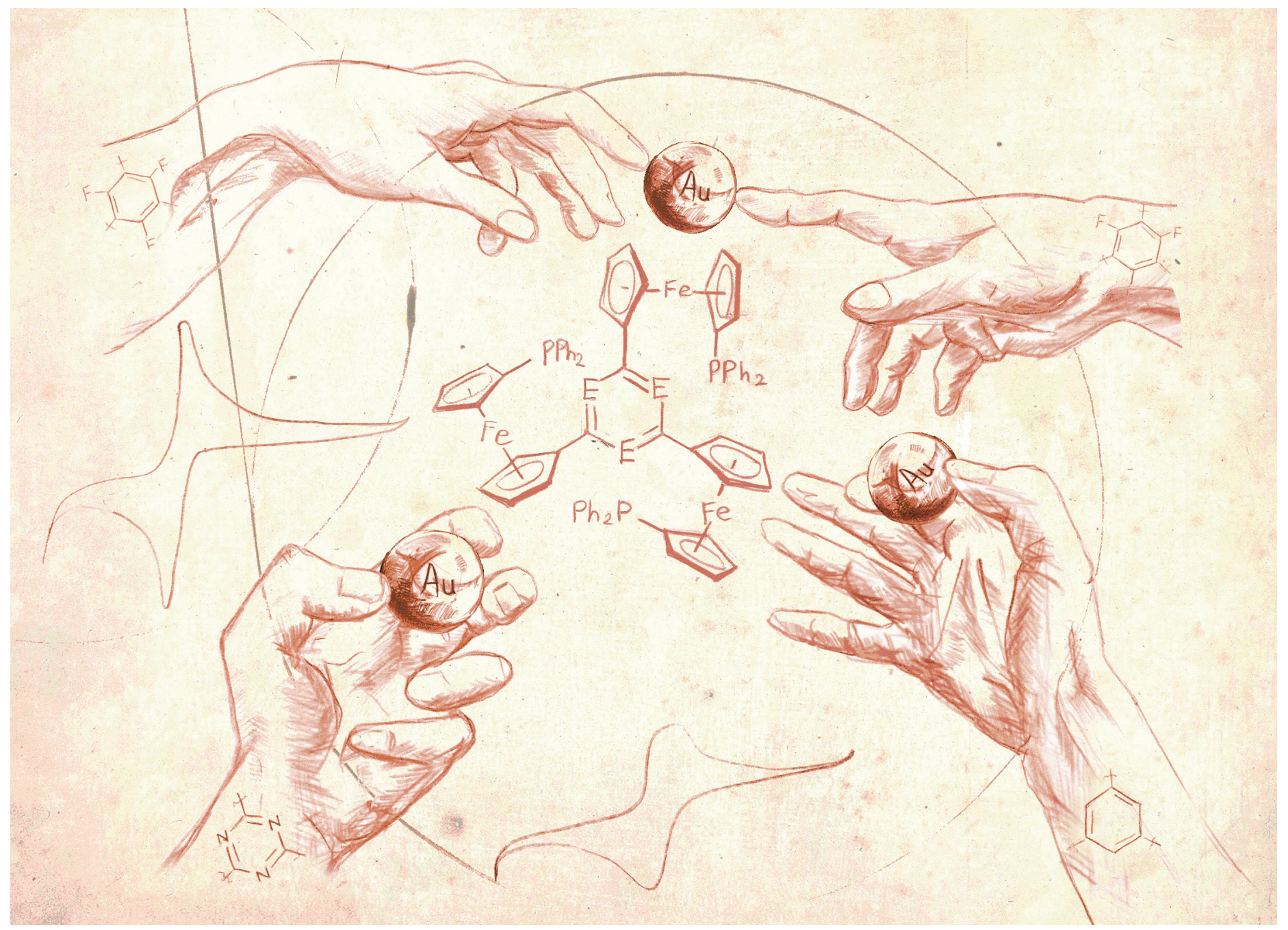

Showcasing collaborative research from the groups of Prof. Evamarie Hey-Hawkins (Universität Leipzig) and Dr. Mark Ringenberg (Universität Stuttgart).

The core of the matter - arene substitution determines the coordination and catalytic behaviour of tris(1-phosphanyl-1'ferrocenylene)arene gold(I) complexes

Depending on the substitution of the central core, tris(1-phosphanyl-1'-ferrocenylene)arenes bind gold(1) in different coordination modes. The resulting complexes are investigated by variable-temperature NMR spectroscopy, DFT calculations, electrochemical methods, and show stepwise activity changes in redox-switchable gold(1) catalysis.

Picture credit: Dr. Christoph Selg, Universität Leipzig (inspired by the styles of the old masters Michelangelo and da Vinci)

\section{As featured in:}

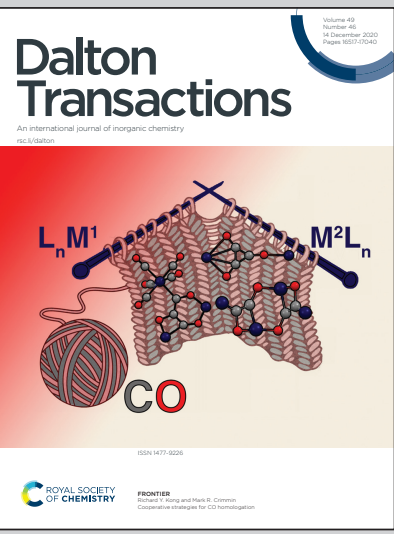

See Evamarie Hey-Hawkins et al., Dalton Trans., 2020, 49, 16667. 


\section{A) Check for updates}

Cite this: Dalton Trans., 2020, 49 16667

\title{
The core of the matter - arene substitution determines the coordination and catalytic behaviour of tris(1-phosphanyl-1'-ferrocenylene)arene gold(I) complexes $\dagger$
}

\author{
Axel Straube, (D) ${ }^{a}$ Peter Coburger, (D) ${ }^{b}$ Marvin Michak, (D) ${ }^{a}$ Mark R. Ringenberg (D) ${ }^{c}$ \\ and Evamarie Hey-Hawkins (iD *a
}

\begin{abstract}
Changing the aromatic core of $\mathrm{C}_{3}$-symmetric tris(ferrocenyl)arene-based tris-phosphanes has profound effects on their coordination behaviour towards gold(I). Depending on the arene (s-triazine, benzene, or trifluorobenzene), four different coordination modes can be distinguished and their preference has been rationalised using computational methods. The corresponding 1:1 ligand-to-metal complexes, studied by variable-temperature NMR spectroscopy, revealed fluctional behaviour in solution. Given the presence of up to three or six ferrocenylene spacers per complex, their electrochemistry was investigated. The redox-responsive nature of the complexes can be advantageously exploited in the catalytic ring-closing isomerisation of $\mathrm{N}$-(2-propyn-1-yl)benzamide, where the benzene-based 2:3 ligand-to-metal complex has been shown to display multiple activity states depending on the degree of (reversible) oxidation in a preliminary trial.
\end{abstract}

Received 5th August 2020

Accepted 14th October 2020

DOI: $10.1039 / \mathrm{d} 0 \mathrm{dt} 02743 \mathrm{j}$

rsc.li/dalton the ligand backbone (I, Chart 1). This is worth pointing out, as ligands built on multi-ferrocene-containing motifs are still comparably scarce, even without putting a focus on RSC. Notable examples include the BIFEP (II) and TRAP (III) ligand families, ${ }^{16,17}$ mesoionic carbene $\mathbf{I V}^{18}{ }^{18}$ terferrocene-based bis(terpyridine) $\mathbf{V},{ }^{19}$ and $C_{2}$-symmetric tetradentate TriFer $\mathbf{V I}{ }^{20}$ Furthermore, a number of discrete multiferrocenyl compounds $\mathrm{s}^{21-27}$ and ferrocenyl-containing dendrimers have been reported over the last years. ${ }^{28-31}$

Conceived as small-molecule analogues of redox-switchable dendrimers, ${ }^{32-34}$ we have recently reported the synthesis of a new family of tris-phosphanes 1 (Chart 1) incorporating a redox-active, $C_{3}$-symmetric tris(ferrocenyl)arene backbone. ${ }^{35}$ Capable of forming both mono- and trinuclear gold(I) complexes (Chart 2), the latter were shown to act as four-state redox-switchable catalysts. The tris-phosphanes are prepared in a modular fashion, and $s$-triazine, benzene, and 1,3,5-trifluorobenzene have been used as central arenes. ${ }^{36}$

As the groups of Lang and Santi have extensively shown, the nature of the arene core is decisive for the electrochemical response of the system both in terms of redox potentials and electronic communication, that is, the existence of mixedvalent oxidised states. ${ }^{21-23,37-49}$ In our case, $1: 1$ ligand-tometal complexes of triazine derivative 1a (Chart 2, left) showed a distinct delocalised coinage metal $-\pi\left(\mathrm{C}_{3} \mathrm{~N}_{3}\right)$ interaction, ${ }^{50}$ while 1:3 ligand-to-gold complexes of 1a-c (Chart 2, right) demonstrated how the electron density of the respective core 

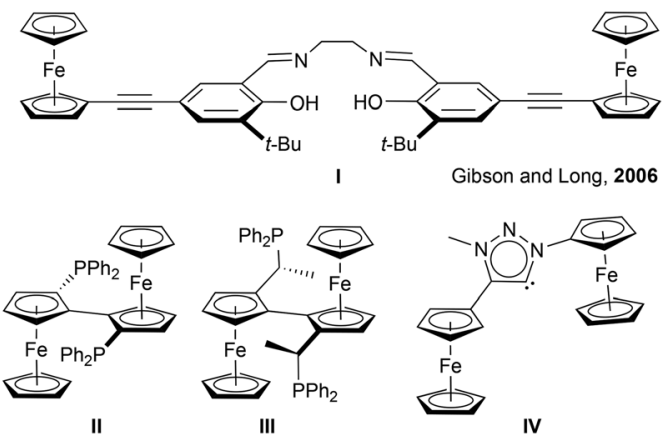

Ito and Sawamura, 1991 Sarkar, 2017
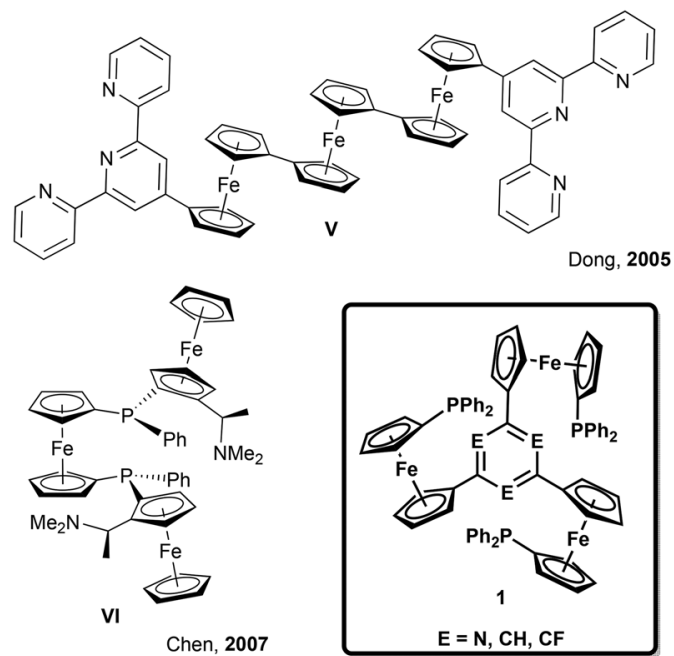

Chart 1 Selected examples of mono- and multidentate ligands with two or more ferrocenyl and ferrocenylene groups in their backbone.

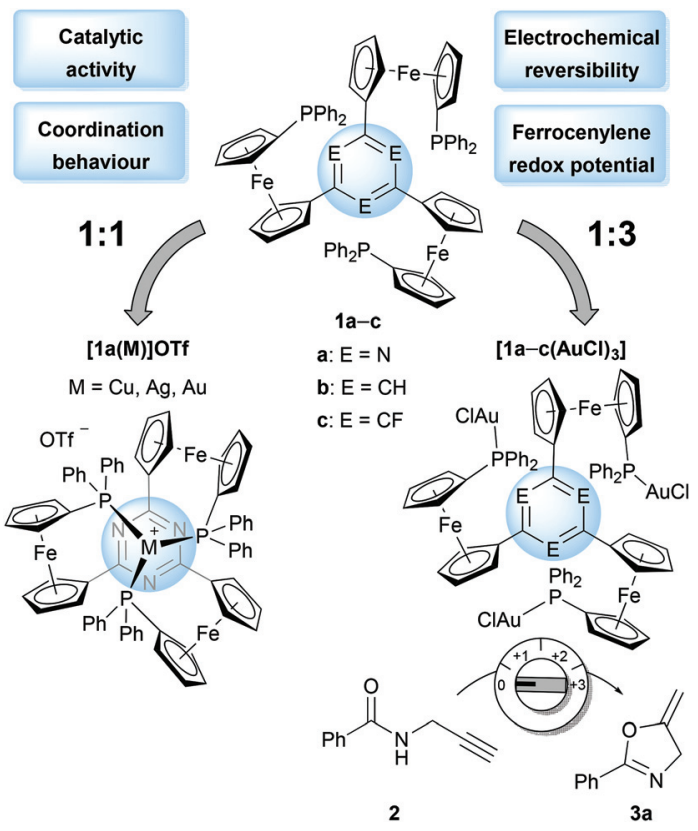

Chart 2 Previous work on the 1:1 ligand-to-metal coinage metal(।) complexes [1a(M)]OTf (left) and on the $1: 3$ ligand-to-metal chloridogold(I) complexes $\left[1 \mathrm{a}-\mathrm{c}(\mathrm{AuCl})_{3}\right]$ (right), showcasing the impact of the arene core on various properties. determined the electrochemical response both with respect to redox potential and reversibility. Furthermore, the arene cores were also found to impact the catalytic activity of these trinuclear gold(I) complexes in the ring-closing isomerisation of $N$-(2-propyn-1-yl)benzamide (2) to 5-methylene-2-phenyl-4,5dihydrooxazole (3a). ${ }^{51}$ Further investigations on the role of the arenes on coordination abilities and catalytic efficacies were thus warranted, and the following contribution details some of our insights.

\section{Results and discussion}

\section{Mononuclear complexes}

Building on the observation of 1a forming trigonal-planar mononuclear complexes with the coinage metals ${ }^{35}$ we first investigated the analogous reaction of benzene-based $\mathbf{1 b}$ with halide-free gold(I) precursor $\left[\mathrm{Au}\left(\eta^{2} \text {-nbe }\right)_{3}\right] \mathrm{OTf}$ (nbe $=$ nornbornene). Gold(I), in contrast to copper(I) and silver(I), ${ }^{52-54}$ tends to be coordinated by arenes in an $\eta^{2}$ fashion with impact on asymmetric induction and catalyst stability. ${ }^{55-60}$ However, more delocalised gold- $\pi$ (arene) interactions are also encountered and deemed important for catalysis and crystal engineering. ${ }^{50,61-65}$ Indeed, when a slight excess of tris-phosphane $\mathbf{1 b}$ was reacted with $\left[\mathrm{Au}\left(\eta^{2} \text {-nbe }\right)_{3}\right]$ OTf in $\mathrm{CH}_{2} \mathrm{Cl}_{2},{ }^{1} \mathrm{H}$ and ${ }^{31} \mathrm{P}\left\{{ }^{1} \mathrm{H}\right\}$ NMR spectra of the reaction mixture (Fig. S5 $\dagger$ ) suggested the formation of a $C_{3 \mathrm{v}}$-symmetric mononuclear complex $[\mathbf{1 b}(\mathbf{A u})]$ OTf with a similar, yet more broadened ${ }^{31} \mathrm{P}\left\{{ }^{1} \mathrm{H}\right\}$ NMR signal than $[\mathbf{1 a}(\mathbf{A u})] \mathrm{OTf}(\delta([\mathbf{1 a}(\mathbf{A u})] \mathbf{O T f})=26.8 \mathrm{ppm}$, $\left.\omega_{1 / 2}=1400 \mathrm{~Hz} ; \delta([\mathbf{1} \mathbf{b}(\mathbf{A u})] \mathbf{O T f})=22.3 \mathrm{ppm}, \omega_{1 / 2}=2130 \mathrm{~Hz}\right)$. Successful purification and isolation of $[\mathbf{1 b}(\mathbf{A u})] \mathbf{O T f}$ was achieved by concentrating a THF extract of the evaporated reaction mixture and storing it at $-25{ }^{\circ} \mathrm{C}$ overnight. Single crystals suitable for X-ray diffraction analysis (XRD) were obtained from a saturated THF solution by slow cooling from $70{ }^{\circ} \mathrm{C}$ to $25{ }^{\circ} \mathrm{C}$ over two days. The molecular structure (Fig. 1, left) revealed only two of three diphenylphosphanyl groups to

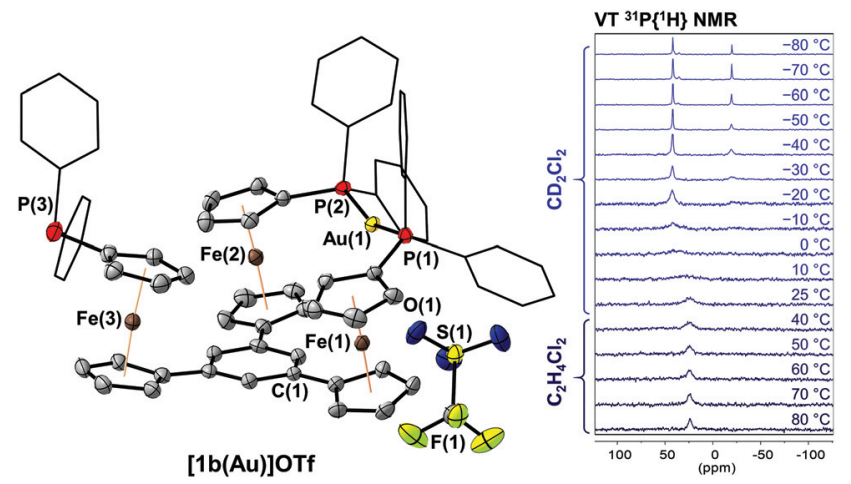

Fig. 1 Left: Molecular structure of [1b(Au)]OTf, thermal ellipsoids set at $50 \%$ probability level. For clarity, $P$-bound phenyl rings are depicted in wireframe style, and co-crystallised solvent and hydrogen atoms are omitted. Right: Variable-temperature ${ }^{31} \mathrm{P}\left\{{ }^{1} \mathrm{H}\right\}$ NMR spectra of [1b(Au)]OTf in $\mathrm{CD}_{2} \mathrm{Cl}_{2}\left(-80{ }^{\circ} \mathrm{C}\right.$ to $\left.25^{\circ} \mathrm{C}\right)$ and $1,2-\mathrm{C}_{2} \mathrm{H}_{4} \mathrm{Cl}_{2}\left(40{ }^{\circ} \mathrm{C}\right.$ to $\left.80^{\circ} \mathrm{C}\right)$, depicted with arbitrary scaling. 
coordinate the gold(I) ion. This starkly contrasts the NMR spectroscopic features which, at $25{ }^{\circ} \mathrm{C}$, suggested $C_{3 \mathrm{v}}$ symmetry.

Crystallographically characterised examples of poly-phosphane gold(I) complexes with pendant, uncoordinated phosphane groups are comparatively rare. ${ }^{66-68}$ The $\mathrm{Au}-\mathrm{P}$ bond lengths of [1 $\mathbf{1 b}(\mathbf{A u})] \mathrm{OTf}(2.3025(8) \AA$ and $2.3017(8) \AA$, Table S2†) and the close-to-linear $\mathrm{P}-\mathrm{Au}-\mathrm{P}$ bond angle of $161.31(4)^{\circ}$ are similar to those observed for a closely related 2,6-bis(1-diphenylphosphanyl-1'-ferrocenylene)pyridine gold(I) complex by Siemeling and Štěpnička, ${ }^{69}$ a related $1,1^{\prime}$-bis(phosphanyl)ferrocene-derived dinuclear gold(I) complex reported by Cowie and Emslie, ${ }^{70}$ and other $\left[\mathrm{Au}\left(\mathrm{PR}_{3}\right)_{2}\right]^{+}$complexes. ${ }^{71-73}$ The triflate anion of $[\mathbf{1} \mathbf{b}(\mathbf{A u})]$ OTf does not seem to strongly interact with the gold(I) centre, as the closest $\mathrm{Au}(1) \cdots \mathrm{O}(1)$ distance of 3.813(3) $\AA$ is just below the sum of the van der Waals radii. ${ }^{74}$

This $P, P^{\prime}$ trans-spanning dicoordinate geometry, constructing a large, formally 12 -membered macrocycle, is not just a solid-state phenomenon, as we were able to demonstrate by variable-temperature (VT) ${ }^{1} \mathrm{H}$ and ${ }^{31} \mathrm{P}\left\{{ }^{1} \mathrm{H}\right\}$ NMR spectroscopy (Fig. 1, right, and Fig. S43 and S44†). Upon heating a 1,2-dichloroethane solution of $[\mathbf{1} \mathbf{b}(\mathbf{A u})] \mathrm{OTf}$ to $80^{\circ} \mathrm{C}$, the very broad ${ }^{31} \mathrm{P}\left\{{ }^{1} \mathrm{H}\right\}$ resonance partly sharpens, while cooling a $\mathrm{CD}_{2} \mathrm{Cl}_{2}$ solution from $25{ }^{\circ} \mathrm{C}$ down to $-80{ }^{\circ} \mathrm{C}$ splits the resonance in two signals at 41.8 and $-19.5 \mathrm{ppm}$ with an integral ratio of $2: 1$. These chemical shifts are in line with those of free $\mathbf{1 b}(\delta=-17.5 \mathrm{ppm})^{36}$ and 2,6-bis(1-diphenylphosphanyl-1'ferrocenylene)pyridine gold(I) $(\delta=42.6 \mathrm{ppm}) .{ }^{69}$ The dynamic behaviour mirrors that of a similarly dicoordinating tris-phosphane by Wade and Gabbaï. ${ }^{66}$ In contrast to triazine-based $[\mathbf{1 a}(\mathbf{A u})] \mathbf{O T f},{ }^{35}$ the low-temperature ${ }^{1} \mathrm{H}$ NMR spectra of [1b(Au)]OTf (Fig. S43†) do not give rise to well-defined sharp resonances. They are, however, in accordance with loss of the apparent $C_{3 \mathrm{v}}$ symmetry observed at and above room temperature which originates from fast coordination/dissociation equilibria.

Since 1,3,5-trifluorobenzene-derived tris-phosphane 1c falls between $\mathbf{1 a}$ and $\mathbf{1 b}$ regarding the electron density of the arene core, the reaction between $1 \mathrm{c}$ and $\left[\mathrm{Au}\left(\eta^{2} \text {-nbe }\right)_{3}\right]$ OTf was investigated next. A mononuclear 1:1 ligand-to-metal complex [1c(Au)]OTf with similar NMR spectral characteristics (Fig. S7-S10†) to [1a(Au)]OTf and [1 $\mathbf{b}(\mathbf{A u})]$ OTf was obtained, again suggesting $C_{3 \mathrm{v}}$ symmetry in solution at $25{ }^{\circ} \mathrm{C}$. Similar to $[\mathbf{1 b}(\mathbf{A u})]$ OTf, $[\mathbf{1 c}(\mathbf{A u})]$ OTf reveals a quickly equilibrating $P, P^{\prime}$ trans-spanning coordination geometry in a multinuclear VT NMR experiment (Fig. S45-S47†); the $C_{3}$-symmetric $P, P^{\prime}, P^{\prime \prime}$ coordination mode is apparently restricted to the $s$-triazine core of $[\mathbf{1 a}(\mathbf{A u})] \mathbf{O T f}$ (vide infra). Attempting purification of the slightly impure product, cooling a THF extract of [1/c(Au)]OTf from $70{ }^{\circ} \mathrm{C}$ to room temperature over two days yielded a few single crystals suitable for XRD. Surprisingly, a onedimensional coordination polymer (CP) $\left\{\left[(\mathbf{1 c})_{2}(\mathbf{A u})_{3}\right](\mathbf{O T f})_{3}\right\}_{n}$ with 2:3 ligand-to-metal stoichiometry had formed in the process (Fig. 2). The structure of $\left\{\left[(1 \mathbf{c})_{2}(\mathbf{A u})_{3}\right](\mathbf{O T f})_{3}\right\}_{n}$ (space group $P \overline{1})$ is characterised by the $\mu_{3}$-connecting, threefold $\kappa^{1}$ coordination mode of ligand 1c, i.e., each phosphane moiety binding one of the three gold(I) ions. The three individual gold(I) centres are close-to-linearly coordinated by two diphenylphosphanyl groups each, and the $\mathrm{P}-\mathrm{Au}-\mathrm{P}$ bond angles (170.45(5)-172.72(5) ${ }^{\circ}, c f$. Table S3 $\dagger$ ) are closer to the ideal $180^{\circ}$ than those found in $[\mathbf{1 b}(\mathbf{A u})] \mathbf{O T f}$, most likely because the 1,3,5-tris(ferrocenyl)arene-derived ligand structure itself does not impose any steric restrictions anymore. The individual

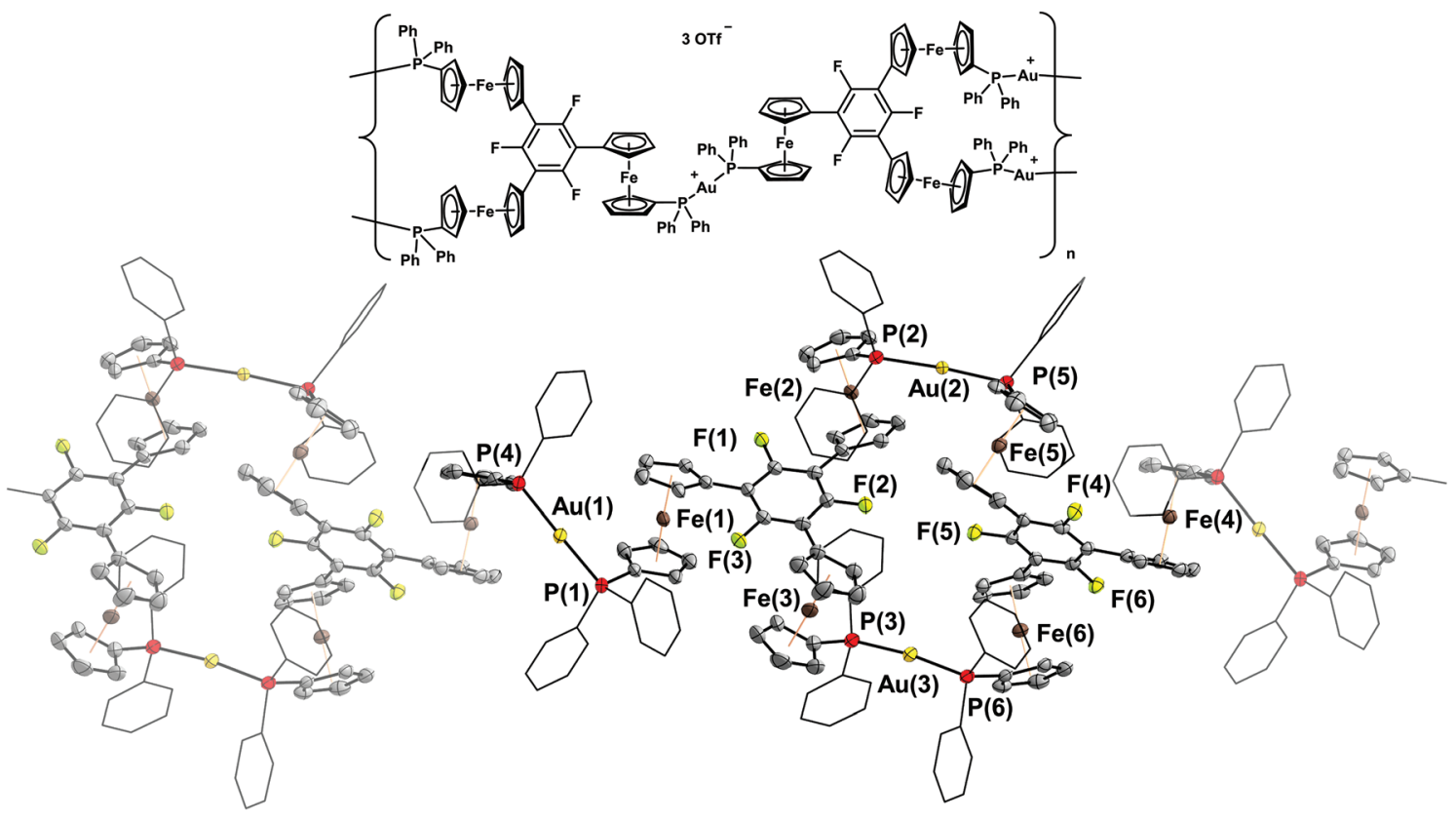

Fig. 2 Top: Chemical structure of coordination polymer $\left\{\left[(1 \mathrm{c})_{2}(\mathrm{Au})_{3}\right](\mathrm{OTf})_{3}\right\}_{n}$ showing the repeating unit. Bottom: Molecular structure of $\left\{\left[(1 \mathrm{c})_{2}(\mathrm{Au})_{3}\right](\mathrm{OTf})_{3}\right\}_{n}$ in the solid state, thermal ellipsoids set at $50 \%$ probability level. For clarity, $P$-bound phenyl rings are depicted in wireframe style, and the three triflate anions as well as hydrogen atoms are omitted. The asymmetric unit of the unit cell is highlighted. 
Au-P bond lengths range from 2.296(1) $\AA$ to 2.320(2) $\AA$ and do not show systematic variations according to their position in the polymeric structure. The individual, non-interacting CP strands propagate in parallel to the crystallographic (001) and along the (110) planes. Small channels (ca. $5.7 \AA \times 8.8 \AA$ ), filled with highly disordered THF molecules, are formed along the crystallographic $a$ axis (Fig. S42†). Upon dissolution of $\left\{\left[(\mathbf{1 c})_{2}(\mathbf{A u})_{3}\right](\mathbf{O T f})_{3}\right\}_{n}$ in $\mathrm{CD}_{2} \mathrm{Cl}_{2}$, the polymeric structure seems to disintegrate; only broad signals are discernible in the respective ${ }^{1} \mathrm{H},{ }^{19} \mathrm{~F}\left\{{ }^{1} \mathrm{H}\right\}$, and ${ }^{31} \mathrm{P}\left\{{ }^{1} \mathrm{H}\right\}$ NMR spectra (Fig. S11-S14 $\dagger$ ). This is in line with HR-ESI mass spectrometry showing fragments with $\mathrm{m} / \mathrm{z}$ values for both monocationic $1: 1$ and tricationic $2: 3$ ligand-to-metal fragments.

Even though the formation of this CP was not intended and its preparation suffers from poor reproducibility, redox-active ferrocene-derived CPs have recently attained great interest for the insight into molecular architecture and self-assembly ${ }^{75-77}$ they provide as well as for their potential applications in catalysis, ${ }^{78,79}$ non-linear optics, and molecular magnetism. ${ }^{77}$ Following the classification of Mochida, $\left\{\left[(\mathbf{1 c})_{2}(\mathbf{A u})_{3}\right](\mathbf{O T f})_{3}\right\}_{n}$ is a one-dimensional main-chain $\mathrm{CP}$ derived from a neutral ligand. ${ }^{77}$ As such it is, to the best of our knowledge, the first $\mathrm{CP}$ to feature a ferrocene-derived tris-phosphane. Phosphanebased CPs are, in general, more elusive than analogues built from nitrogen- or sulfur-containing ligands, ${ }^{80}$ and often constructed around gold(I) with its tendency for simple coordination geometries and formative aurophilic interactions. ${ }^{81-83}$ Last but not least, the 2:3 ligand-to-metal stoichiometry of $\left\{\left[(\mathbf{1 c})_{2}(\mathbf{A u})_{3}\right](\mathbf{O T f})_{3}\right\}_{n}$ is also uncommon among CPs, a cadmium(II)-based CP by Tian and co-workers being the only other example. ${ }^{84}$

In light of 1a-c showing three different coordination modes for gold(I), this unexpected behaviour was studied by an energy decomposition analysis using density-functional theory (DFT) level calculations (for computational details, s. ESI, section $1.1 \dagger$ ). Geometry optimisations and energy calculations for both the closed tricoordinate, $C_{3}$-symmetric coordination mode (observed for [1a(Au)]OTf) and the open dicoordinate, $C_{\mathrm{s}}$-symmetric coordination mode (observed for [1 $\left.\mathbf{1 b}(\mathbf{A u})\right] \mathbf{O T f}$ in the solid state and in solution, and for [1c(Au)]OTf in solution) were conducted for gold(I) complexes of the three ligands 1a-c, excluding the triflate counterion in all cases (Fig. S54-S62†). The total coordination energy $E_{\text {coord }}$, the energy gain upon combining the (native) tris-phosphane and a gold(I) ion, can be split into two contributions, namely the preparation energy $E_{\text {prep }}$ (required to form the geometry of the coordinated ligand from the native tris-phosphane, representing steric contributions) and the interaction energy $E_{\text {inter }}$ (gained from the interaction between the isolated gold(I) ion and the pre-formed ligand, representing electronic contributions). Comparing the obtained values for all six complexes (Fig. 3, Tables 1 and S4†), the decisive role of the preparation energy becomes clear. Obviously, steric repulsion between the constituting arene fragments $\mathbf{E}(\mathrm{N} \mid, \mathrm{C}-\mathrm{H}, \mathrm{C}-\mathrm{F})$ and the ortho hydrogen atoms of the $C$-bound cyclopentadienyl rings governs the coordination geometry. The close-to co-planar arrangement of the three

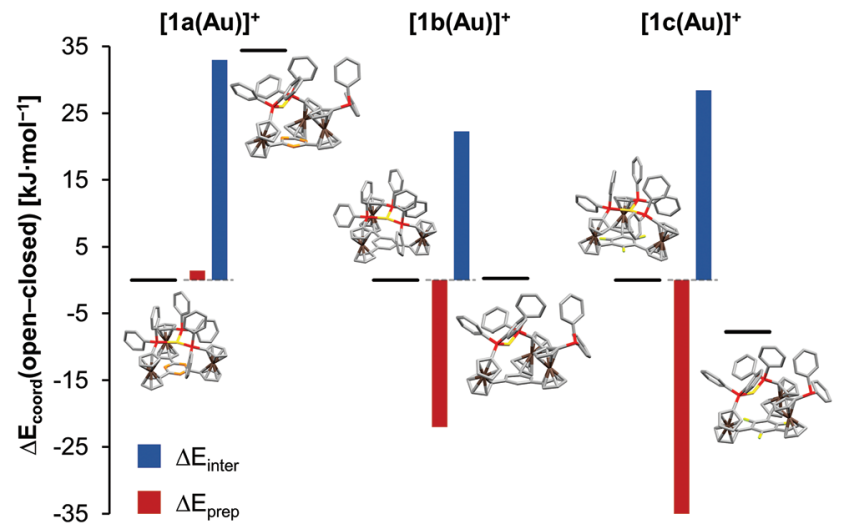

Fig. 3 Total coordination energy difference $\Delta E_{\text {coord }}$ between open (dicoordinate) and closed (tricoordinate) forms of mononuclear complexes $[1 \mathrm{a}-\mathrm{c}(\mathrm{Au})]^{+}$(black horizontal bars) and the respective contributions from interaction ( $\Delta E_{\text {inter, }}$, blue columns) and preparation ( $\Delta E_{\text {prep }}$, red columns) energies obtained from calculations at the DFT level.

Table 1 Calculated total coordination $\left(E_{\text {coord }}\right)$, preparation $\left(E_{\text {prep }}\right)$, and interaction $\left(E_{\text {inter }}\right)$ energies for open (dicoordinate) and closed (tricoordinate) geometries of mononuclear gold(I) complexes of $1 \mathrm{a}-\mathrm{c}$ and arenecyclopentadienyl torsions $\varphi$ of the respective structures (DFT level, conductor-like polarisable continuum solvent model [CPCM; $\mathrm{CH}_{2} \mathrm{Cl}_{2}$ ] applied)

\begin{tabular}{|c|c|c|c|c|c|}
\hline & & $\begin{array}{l}E_{\text {coord }} \\
{\left[\mathrm{kJ} \mathrm{mol}^{-1}\right.}\end{array}$ & ${ }^{1}{ }_{\text {prep }}$ & $E_{\text {inter }}$ & $\varphi^{a}\left[{ }^{\circ}\right]$ \\
\hline \multirow{3}{*}[\mathbf{1a}(\mathbf{Au})]{$^{+}$} & Open & -476.8 & +47.9 & -524.7 & $27.4,28.3$ \\
\hline & Closed & -511.2 & +46.5 & -557.7 & $8.9-9.2(8.3-10.4)^{b}$ \\
\hline & $\Delta(\mathrm{o}-\mathrm{c})$ & +34.4 & +1.4 & +33.0 & \\
\hline \multirow{3}{*}[\mathbf{1b}(\mathbf{Au})]{$^{+}$} & Open & -508.8 & +18.0 & -526.8 & $32.3,42.0(11.6,13.1)^{c}$ \\
\hline & Closed & -509.1 & +40.0 & -549.1 & $13.8-14.0$ \\
\hline & $\Delta(\mathrm{o}-\mathrm{c})$ & +0.3 & -22.0 & +22.3 & \\
\hline \multirow[t]{3}{*}[\mathbf{1c}(\mathbf{Au})]{$^{+}$} & Open & -499.1 & +25.3 & -524.4 & $32.9,42.0(27.4-34.1)^{a}$ \\
\hline & Closed & -491.4 & +61.5 & -552.9 & $11.4-25.0$ \\
\hline & $\Delta(\mathrm{o}-\mathrm{c})$ & -7.8 & -36.2 & +28.5 & \\
\hline
\end{tabular}

${ }^{a}$ Torsion between arene-bound cyclopentadienyl rings of coordinating 1-diphenylphosphanyl-1'-ferrocenylene group and central arene. ${ }^{b}$ Experimentally determined values for [1a(Au)]OTf. ${ }^{35}{ }^{c}$ Experimentally determined values for $[\mathbf{1 b}(\mathbf{A u})] \mathbf{O T f} .{ }^{d}$ Experimentally determined values for $\left\{\left[(1 \mathrm{c})_{2}(\mathrm{Au})_{3}\right](\mathrm{OTf})_{3}\right\}_{n}$.

cyclopentadienyl rings and the arene core, a feature of the $C_{3}$-symmetric closed geometry, is therefore less feasible, and open structures become more attractive. Correspondingly, the fluorine atoms, largest in this series, lead to the highest arenecyclopentadienyl torsion $\varphi$ both in the calculated and in the experimentally determined structures of $1 \mathbf{c}$ (Table 1 ). In terms of interaction energies $E_{\text {inter }}$, the closed form is more favourable in all cases, likely owing to a higher coordination number (3 vs. 2) and attractive gold- $\pi$ (arene) interactions increasing in strength from benzene over 1,3,5-trifluorobenzene to $s$-triazine. These findings might explain the formation of coordination polymer $\left\{\left[(\mathbf{1 c})_{2}(\mathbf{A u})_{3}\right](\mathbf{O T f})_{3}\right\}_{n}$ from $[\mathbf{1 c}(\mathbf{A u})]$ OTf. As the experimentally determined $\varphi$ values are the highest in the series of the three solid-state structures (Table 1), the $\mu_{3}: \kappa^{1} P, \kappa^{1} P^{\prime}, \kappa^{1} P^{\prime \prime}$ coordination mode of $\mathbf{1 c}$ apparently accommodates the clash- 
ing ortho fluorine atoms and cyclopentadienyl ring protons most easily. For the borderline case of $[\mathbf{1} \mathbf{b}(\mathbf{A u})] \mathbf{O T f}$, the conformation influence of the pendant ferrocenylphosphane was probed by comparing two extreme conformations (all-syn as found in the solid-state structures of both $\mathbf{1 b}$ and $[\mathbf{1 b}(\mathbf{A u})]$ OTf vs. a syn,anti,anti arrangement; Fig. S65 $\dagger$ ). While this conformation was found to be significantly less stable than the allsyn conformer by about $50 \mathrm{~kJ} \mathrm{~mol}^{-1}$, the initial geometry of $\mathbf{1 b}$ was shown to be irrelevant for the outcome of the analysis in that the experimentally found all-syn structure of $[\mathbf{1 b}(\mathbf{A u})] \mathbf{O T f}$ was the most stable one.

Intrigued by the possibility of modifying the coordination properties of tris(ferrocenylene)arene-based tris-phosphanes via the substitution pattern of the arene, we next introduced fluorine in the diphenylphosphanyl groups of $\mathbf{1 a}$ in form of the bis(pentafluorophenyl)phosphanyl moiety $\left[\mathrm{P}\left(\mathrm{Ph}^{\mathrm{F}}\right)_{2}\right]$ (Chart 3). With regard to (redox-switchable) gold(I) catalysis, the $\mathrm{P}\left(\mathrm{Ph}^{\mathrm{F}}\right)_{2}$ moiety is of considerable interest due to its very low $\sigma$-donor capability. ${ }^{85,86}$ The resulting electronpoor gold(I) centres show great potential in gold(I)-catalysed multiple bond activation ${ }^{87-91}$ and could also be of interest in gold(I)-catalysed oxidative addition reactions. ${ }^{92}$ Besides catalyst design, the $\mathrm{P}\left(\mathrm{Ph}^{\mathrm{F}}\right)$ moiety has also found applications in the preparation of stimuli-responsive fluorescent metal complexes $^{93}$ and organic materials with intriguing optoelectronic properties. ${ }^{94,95}$

To date, ferrocene-based derivatives are rare, and only the 1,1'-diphenylphosphanylferrocene (dppf) analogue VII $^{96-98}$ and a FcPHOX derivative VIII (Chart 3) ${ }^{99}$ have been prepared and used for complexation of palladium(II). Tris-phosphane $\mathbf{1 a}^{\mathbf{F}}$ can be prepared from 2,4,6-tris(1-bromo-1'-ferrocenylene)1,3,5-triazine 4 a, albeit in a low yield of only $15 \%$, still highlighting the modular preparation of tris-phosphanes 1 . The NMR chemical shifts of $\mathbf{1} \mathbf{a}^{\mathbf{F}}$, an air- and moisture-stable, deep

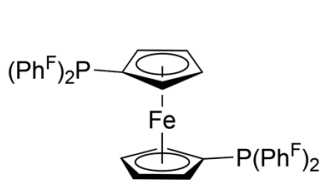

VII

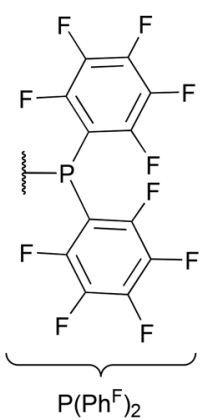

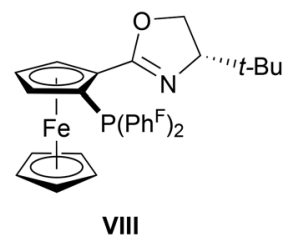

VIII

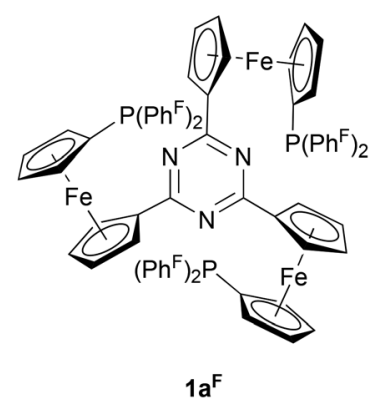

Chart 3 Previously reported ferrocene-based bis(pentafluorophenyl)phosphanes VII and VIII, and bis(pentafluorophenyl)phosphane derivative $1 \mathrm{a}^{\mathrm{F}}$. red microcrystalline solid, in ${ }^{19} \mathrm{~F}\left\{{ }^{1} \mathrm{H}\right\}$ and ${ }^{31} \mathrm{P}\left\{{ }^{1} \mathrm{H}\right\}$ NMR spectroscopy match those of VII very well. ${ }^{96,100}$

Reacting $\mathbf{1 a}^{\mathbf{F}}$ with $\left[\mathrm{Au}\left(\eta^{2} \text {-nbe }\right)_{3}\right]$ OTf in $\mathrm{CH}_{2} \mathrm{Cl}_{2}$ resulted in a less clean conversion than anticipated, and only after several recrystallisation steps could a few crystals suitable for XRD be obtained. [1 $\left.\mathbf{a}^{\mathbf{F}}(\mathbf{A u})\right]$ OTf is the first crystallographically characterised example of a ferrocene-derived ligand featuring any $\mathrm{P}\left(\mathrm{Ph}^{\mathrm{F}}\right)$ group and, among the few reported gold(I) complexes of this donor, the only example of a bidentate phosphane. ${ }^{101-103}$ The solid-state structure of $\left[\mathbf{1 a}^{\mathbf{F}}(\mathbf{A u})\right] \mathbf{O T f}$ (Fig. 4, top) differs only slightly from that of $[\mathbf{1} \mathbf{b}(\mathbf{A u})] \mathbf{O T f}$. Both complexes share the $C_{\mathrm{s}}$-symmetric, $P, P^{\prime}$-dicoordinate geometry with a pendant phosphane group. Apparently, the steric strain imposed by the H-to-F substitution on the $P$-bound phenyl rings outweighs the energy gain by the attractive gold $(\mathrm{I})-\pi\left(\mathrm{C}_{3} \mathrm{~N}_{3}\right)$ interaction. ${ }^{85}$ Even though a DFT-level geometry optimisation of the corresponding $C_{3}$-symmetric tricoordinate gold(I) complex cation $\left[\mathbf{1 a}^{\mathbf{F}}(\mathbf{A u})\right]_{\text {closed }}{ }^{+}$initially suggested the synthetic accessibility of this coordination mode, the open form $\left[\mathbf{1 a}^{\mathbf{F}}(\mathbf{A u})\right]_{\text {open }}{ }^{+}$was found to be energetically far more favourable by $207 \mathrm{~kJ} \mathrm{~mol}^{-1}$ (section 4 of the ESI $\dagger$ ). While $\left[\mathbf{1 a}^{\mathbf{F}}(\mathbf{A u})\right]$ OTf shows marginally shorter Au-P bond lengths and a slightly increased $\mathrm{P}(1)-\mathrm{Au}-\mathrm{P}(2)$ bond angle (Table 2), the most notable difference
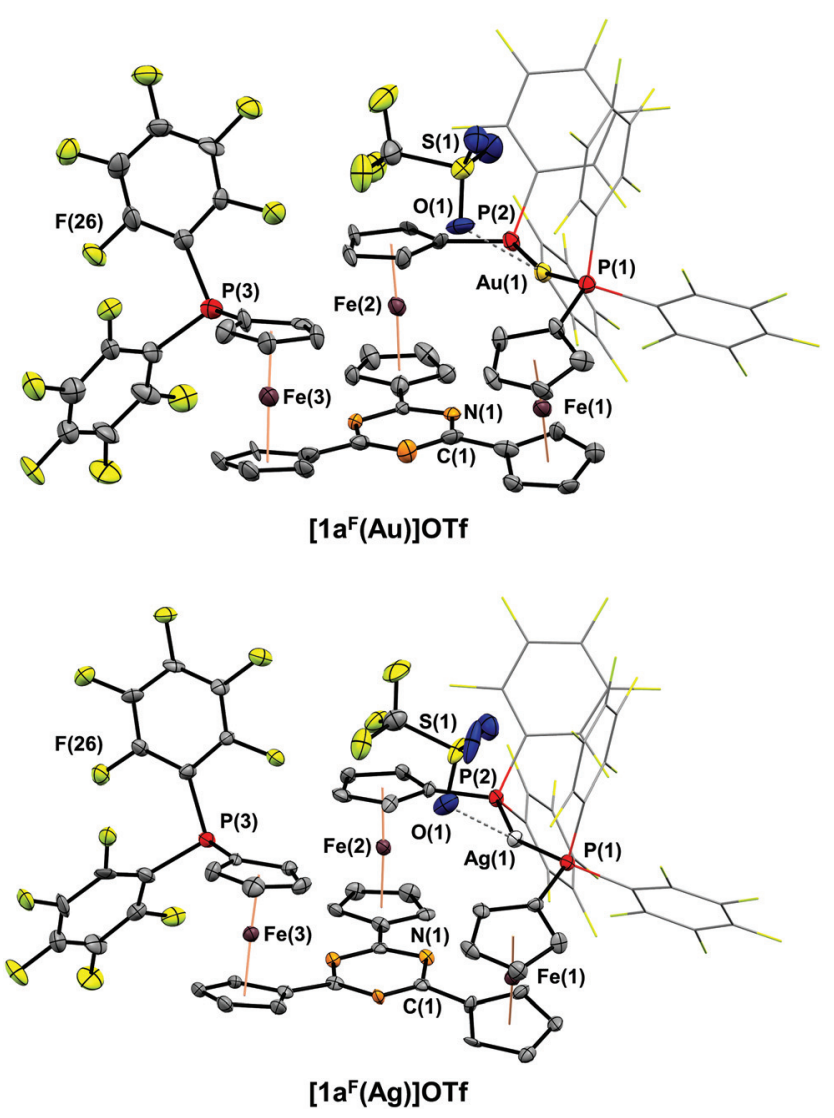

Fig. 4 Molecular structures of $\left[1 \mathrm{a}^{\mathrm{F}}(\mathrm{Au})\right] \mathrm{OTf}$ (top) and $\left[1 \mathrm{a}^{\mathrm{F}}(\mathrm{Ag})\right] \mathrm{OTf}$ (bottom), thermal ellipsoids set at $30 \%$ probability level. For clarity, pentafluorophenyl rings of the coordinating phosphanes are depicted in wireframe style, and co-crystallised solvent and hydrogen atoms are omitted. 
Table 2 Selected bond lengths, distances, and angles of mononuclear complexes [1b(Au)]OTf, [1a $\left.\left.\mathrm{F}^{(\mathrm{Au})}\right)\right] \mathrm{OTf}$, and [1a $\left.{ }^{\mathrm{F}}(\mathrm{Ag})\right] \mathrm{OTf}$

\begin{tabular}{|c|c|c|c|}
\hline & {$[\mathbf{1 b}(\mathrm{Au})] \mathrm{OTf}$} & {$\left[1 \mathbf{a}^{\mathbf{F}}(\mathrm{Au})\right] \mathrm{OTf}$} & {$\left[1 \mathrm{a}^{\mathrm{F}}(\mathrm{Ag})\right] \mathrm{OTf}$} \\
\hline $\mathrm{M}(1) \cdots \mathrm{O}(1)^{a}[\AA]$ & $3.813(3)$ & $3.08(1)$ & $2.57(1)$ \\
\hline
\end{tabular}

${ }^{a} \mathbf{M}(1)=\mathrm{Au}$ for $[\mathbf{1 b}(\mathbf{A u})] \mathbf{O T f}$ and $\left[\mathbf{1 a}^{\mathbf{F}}(\mathbf{A u})\right] \mathbf{O T f}, \mathbf{M}(1)=\mathrm{Ag}$ for $\left[\mathbf{1 a}^{\mathbf{F}}(\mathbf{A g})\right] \mathbf{O T f}$.

to $[\mathbf{1 b}(\mathbf{A u})] \mathrm{OTf}$ lies in the much shorter $\mathrm{Au} \cdots \mathrm{O}$ (triflate) distance of only 3.08(1) ^, well below the sum of the van der Waals radii $(3.82 \AA),{ }^{74}$ yet significantly above the sum of the covalent radii $(2.02 \AA) .{ }^{104}$ In a multinuclear VT NMR spectroscopy experiment of $\left[\mathbf{1 a}^{\mathbf{F}}(\mathbf{A u})\right] \mathbf{O T f}$ in $\mathrm{CD}_{2} \mathrm{Cl}_{2}$ (Fig. 5, left, and Fig. S51-S53†), no significant broadening of the triflate ${ }^{19} \mathrm{~F}\left\{{ }^{1} \mathrm{H}\right\}$ resonance $\left({ }^{*}\right)$ is observed lowering the temperature from $25{ }^{\circ} \mathrm{C}$ to $-60{ }^{\circ} \mathrm{C}$, speaking against a strong interaction in solution. In contrast to $[\mathbf{1 b}(\mathbf{A u})] \mathbf{O T f}$ and $[\mathbf{1 c}(\mathbf{A u})] \mathbf{O T f}$, the dicoordinate bonding mode is apparent from signals for the pendant phosphane group (\#) already at $25{ }^{\circ} \mathrm{C}$ in both the ${ }^{19} \mathrm{~F}\left\{{ }^{1} \mathrm{H}\right\}$ and the ${ }^{31} \mathrm{P}\left\{{ }^{1} \mathrm{H}\right\}$ NMR spectra (Fig. 5, left) and does not seem to be fluctional. The ${ }^{19} \mathrm{~F}\left\{{ }^{1} \mathrm{H}\right\}$ NMR signals attributable to the coordinated $\mathrm{P}\left(\mathrm{Ph}^{\mathrm{F}}\right)_{2}$ groups of $\left[\mathbf{1} \mathbf{a}^{\mathrm{F}}(\mathbf{A u})\right] \mathbf{O T f}$, very broad and hardly discriminable from the baseline at $25{ }^{\circ} \mathrm{C}$, sharpen significantly and partly decoalesce (dashed lines) upon cooling.
This points to free (A) vs. partly hindered rotation (B) about the $\mathrm{P}-\mathrm{C}\left(\mathrm{Ph}^{\mathrm{F}}\right)$ bonds of the two $P$-bound pentafluorophenyl groups involved in coordination (Fig. 5, top left). The assignment of the resonances to either ring has been established through a ${ }^{19} \mathrm{~F},{ }^{19} \mathrm{~F}$ COSY NMR experiment, but the relative orientation of the $\mathrm{Ph}^{\mathrm{F}}$ rings is not clear. Warming the same solution to $45{ }^{\circ} \mathrm{C}$ does not result in apparent $C_{3 \mathrm{v}}$ but in a clearer $C_{\mathrm{s}}$ molecular symmetry for both nuclei.

The loss of symmetry is also apparent from the corresponding ${ }^{1} \mathrm{H}$ NMR spectra. At $25{ }^{\circ} \mathrm{C}$, the ${ }^{1} \mathrm{H}$ NMR spectrum of $\left[\mathbf{1 a}^{\mathrm{F}}(\mathbf{A u})\right] \mathrm{OTf}$ is difficult to assign due to significant broadening of the signals. At $-60{ }^{\circ} \mathrm{C}, 11$ distinct signals with matching integrals for the 12 protons of a $C_{\mathrm{s}}$-symmetric species can be identified (the signal at $4.45 \mathrm{ppm}$ contributing with a relative integral of 2). The mononuclear composition in solution is also confirmed by HR-ESI mass spectrometry.

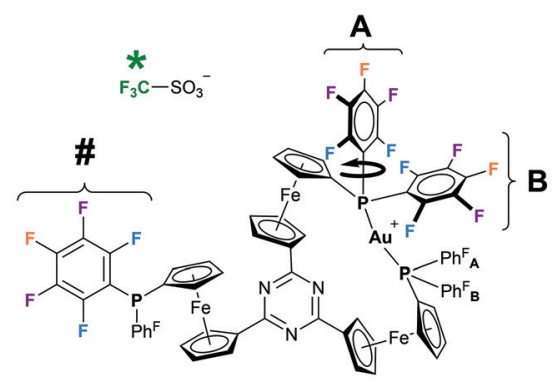

High temperature

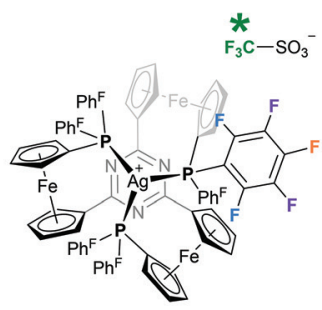

Low temperature

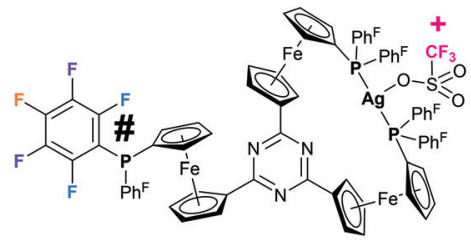

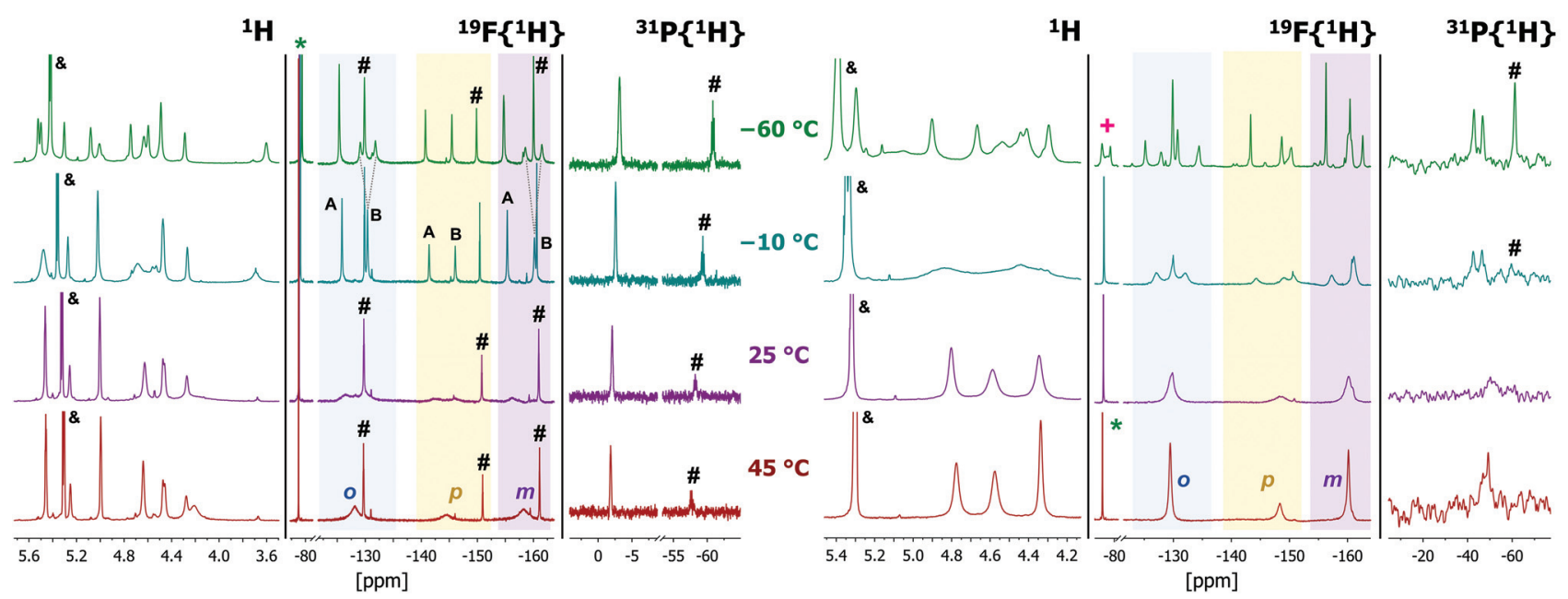

Fig. 5 Sections of the variable-temperature ${ }^{1} \mathrm{H},{ }^{19} \mathrm{~F}\left\{{ }^{1} \mathrm{H}\right\}$, and ${ }^{31} \mathrm{P}\left\{{ }^{1} \mathrm{H}\right\}$ NMR spectra of $\left[1 \mathrm{a}^{\mathrm{F}}(\mathrm{Au})\right] \mathrm{OTf}$ (left) and $\left[1 \mathrm{a}^{\mathrm{F}}(\mathrm{Ag})\right] \mathrm{OTf}$ (right) in $\mathrm{CD} \mathrm{Cl}_{2}$ (\&: $\mathrm{CHDCl}_{2} / \mathrm{CH}_{2} \mathrm{Cl}_{2}$ resonance; *: triflate anion resonance; +: split triflate anion resonance of [1a $\left.{ }^{\mathrm{F}}(\mathrm{Ag})\right] \mathrm{OTf}$; \#: pendant $\mathrm{P}\left(\mathrm{Ph}^{\mathrm{F}}\right)_{2}$ group). The shaded areas in the ${ }^{19} \mathrm{~F}\left\{{ }^{1} \mathrm{H}\right\}$ NMR spectra correspond to the spectral regions of the ortho (blue), para (orange), and meta fluorine substituents of the $\mathrm{P}\left(\mathrm{Ph}^{\mathrm{F}}\right)_{2}$ groups. 
Since we were unable to obtain satisfactorily pure samples and sufficient amounts of $\left[\mathbf{1 a}^{\mathbf{F}}(\mathbf{A u})\right]$ OTf for further analyses or applications, we turned our attention to the reaction of $\mathbf{1 a}^{\mathbf{F}}$ with silver(I) triflate. In the corresponding complex of 1a, the silver(I) $-\pi\left(\mathrm{C}_{3} \mathrm{~N}_{3}\right)$ interaction had been found stronger than for the gold(I) analogue. ${ }^{35}$ While the formation and isolation of $\left[\mathbf{1 a}^{\mathbf{F}}(\mathbf{A g})\right] \mathbf{O T f}$ proved much more facile, the solid-state molecular structure (Fig. 4, bottom) is analogous to that of the gold(I) congener. As previously noted for isostructural pairs of silver(I) and gold(I) complexes, the $\mathrm{M}-\mathrm{P}$ bonds (Table 2) are longer for the silver(I) complex..$^{35,71,105}$ The $\mathrm{P}(1)-\mathrm{Ag}(1)-\mathrm{P}(2)$ bond angle deviates more strongly from the ideal $180^{\circ}$, paralleled by a shorter $\operatorname{Ag}(1) \cdots \mathrm{N}(1)$ distance of $3.89(1) \AA$ $\left(\left[\mathbf{1 a}^{\mathbf{F}}(\mathbf{A u})\right]\right.$ OTf: $\left.4.14(1) \AA\right)$. Moreover, a significantly closer contact between the triflate anion and the silver(I) cation $(d(\mathrm{Ag}(1) \cdots \mathrm{O}(1))=2.57(1) \AA)$ can be discerned. While this distance is still well above the sum of the covalent radii $(2.11 \AA),{ }^{104}$ its deviation from the sum of the van der Waals radii $(4.03 \AA)$ is far greater than in $\left[\mathbf{1} \mathbf{a}^{\mathbf{F}}(\mathbf{A u})\right]$ OTf.

$\left[1 \mathbf{a}^{\mathbf{F}}(\mathbf{A g})\right] \mathbf{O T f}$ is, to the best of our knowledge, the first silver complex of a pentafluorophenylphosphane (one example of a corresponding phosphanido complex, formed by $\mathrm{C}_{6} \mathrm{~F}_{5}$ group transfer from $\mathrm{AgC}_{6} \mathrm{~F}_{5}$ to a $\mathrm{PCl}_{2}$ moiety, has been reported by Schulz and co-workers). ${ }^{106}$ Despite their similar structures, the silver(I) complex deviates from the gold(I) analogue in its (VT) NMR-spectroscopic features (Fig. 5, right, and Fig. S48-S50†).

Above $5{ }^{\circ} \mathrm{C},\left[\mathbf{1} \mathbf{a}^{\mathbf{F}}(\mathbf{A g})\right]$ OTf appears $C_{3 \mathrm{v}}$-symmetric in $\mathrm{CD}_{2} \mathrm{Cl}_{2}$ solution in the corresponding ${ }^{1} \mathrm{H}$ and ${ }^{31} \mathrm{P}\left\{{ }^{1} \mathrm{H}\right\}$ NMR spectra (Fig. 5, top right, and Fig. S48, S49†); coalescence in the ${ }^{19} \mathrm{~F}\left\{{ }^{1} \mathrm{H}\right\}$ NMR spectra occurs only at higher temperatures. Upon cooling, the ${ }^{31} \mathrm{P}\left\{{ }^{1} \mathrm{H}\right\}$ resonance decoalesces into a $2: 1$ pattern indicative of the $P, P^{\prime}$-dicoordinate bonding mode, and the signal for the silver-bound phosphane further splits into a doublet due to unresolved ${ }^{1} J$ coupling with both ${ }^{107 / 109} \mathrm{Ag}$ isotopes. The close silver-triflate contact of the molecular structure is also observed in the ${ }^{19} \mathrm{~F}\left\{{ }^{1} \mathrm{H}\right\}$ NMR spectra below $-30{ }^{\circ} \mathrm{C}$ due to a strong splitting of the triflate- $\mathrm{CF}_{3}$ resonance $(+)$, clearly setting $\left[\mathbf{1 a}^{\mathbf{F}}(\mathbf{A g})\right] \mathbf{O T f}$ apart from $\left[\mathbf{1 a}^{\mathbf{F}}(\mathbf{A u})\right] \mathbf{O T f}$. Furthermore, the low-temperature ${ }^{1} \mathrm{H}$ and ${ }^{19} \mathrm{~F}\left\{{ }^{1} \mathrm{H}\right\} \quad$ NMR spectra of $\left[\mathbf{1 a}^{\mathbf{F}}(\mathbf{A g})\right]$ OTf are more complex, and no unambiguous assignments could be made.

\section{Trinuclear complexes}

Incited by the adventitious formation of $\left\{\left[(\mathbf{1 c})_{2}(\mathbf{A u})_{3}\right](\mathbf{O T f})_{3}\right\}_{n}$ and the presence of pendant phosphane groups in the mononuclear complexes of $\mathbf{1 b}$ and $\mathbf{1 c}$ in contrast to those of $\mathbf{1 a}, \mathbf{1 a}-\mathbf{c}$ were reacted with $\left[\mathrm{Au}\left(\eta^{2} \text {-nbe }\right)_{3}\right]$ OTf in a $2: 3$ ligand-to-metal ratio similar to that found for CP $\left\{\left[(\mathbf{1 c})_{2}(\mathbf{A u})_{3}\right](\mathbf{O T f})_{3}\right\}_{n}$. Indeed, both $1 \mathrm{a}$ and $\mathbf{1 b}$ reacted to form well-defined trinuclear complexes $\left[(\mathbf{1 a})_{2}(\mathbf{A u})_{3}\right](\mathbf{O T f})_{3}$ and $\left[(\mathbf{1 b})_{2}(\mathbf{A u})_{3}\right](\mathbf{O T f})_{3}$ which could be crystallised from $\mathrm{CH}_{2} \mathrm{Cl}_{2}$ and toluene and fully characterised. In contrast, despite testing variations of stoichiometry as well as different purification and crystallisation protocols, discrete trinuclear gold(I) complexes of 1c could not be obtained and only ill-defined, potentially oligomeric products with varying ${ }^{31} \mathrm{P}\left\{{ }^{1} \mathrm{H}\right\}$ NMR signals around $40 \mathrm{ppm}$ were formed.
The molecular structures of $\left[(\mathbf{1 a})_{2}(\mathbf{A u})_{3}\right](\mathbf{O T f})_{3}$ and $\left[(\mathbf{1 b})_{2}(\mathbf{A u})_{3}\right](\mathbf{O T f})_{3}$ (Fig. 6 top and centre) can be understood as two mononuclear, $P, P^{\prime}$-dicoordinate complexes linked by a third gold(I) ion coordinated by the remaining phosphane. Thus, even though the ligand-to-metal stoichiometry of $2: 3$ is formally identical to that of $\left\{\left[(\mathbf{1 c})_{2}(\mathbf{A u})_{3}\right](\mathbf{O T f})_{3}\right\}_{n}$, the discrete trinuclear complexes contain $\mathbf{1 a}$ and $\mathbf{1 b}$ in a different, $\mu_{2}: \kappa^{1} P, \kappa^{2} P^{\prime}, P^{\prime \prime}$ coordination mode. In general, trinuclear gold(I) complexes formed from two tris-phosphanes (or other $P$-donors) are relatively scarce in the literature and mostly contain linear $\mathrm{Au}_{3}$ chains. ${ }^{107-111}$ The particular coordination mode observed here has not yet been reported for solid-state structures deposited in the Cambridge Structural Database. ${ }^{112}$ As a result of the packing, which does not involve aurophilic interactions or close contacts between the individual tricationic molecules, small and large channels are formed along the crystallographic $a$ axis (Fig. 6, bottom). The smaller channels (approx. diameter of $5.3 \AA$ ) are occupied by the severely disordered triflate anions. Only a single one in the structure

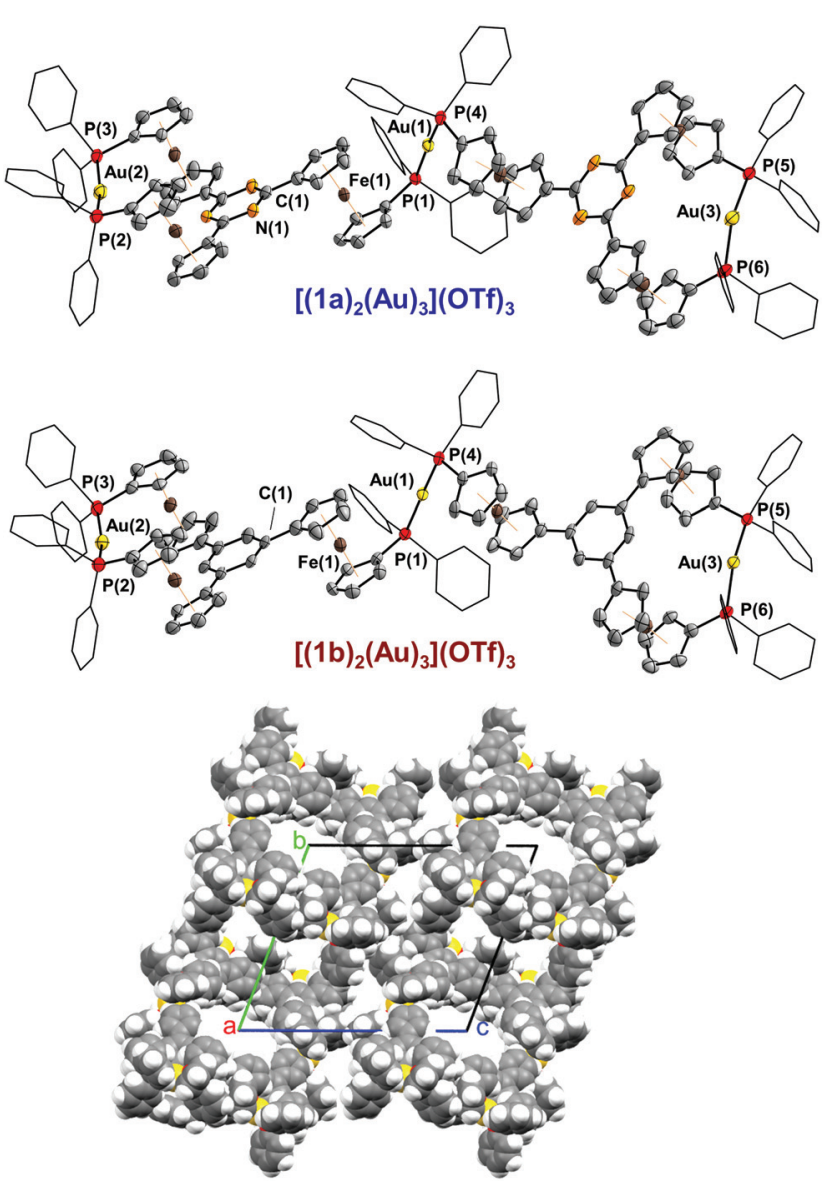

Fig. 6 Molecular structures of $\left[(1 \mathrm{a})_{2}(\mathrm{Au})_{3}\right](\mathrm{OTf})_{3}$ (top) and $\left[(\mathrm{Bb})_{2}(\mathrm{Au})_{3}\right](\mathrm{OTf})_{3}$ (centre). Thermal ellipsoids set at $50 \%$ probability level. For clarity, $P$-bound phenyl groups are depicted in wireframe style, and co-crystallised solvent, anions, and hydrogen atoms are omitted. Bottom: Spacefilling model of $\left[(1 b)_{2}(\mathrm{Au})_{3}\right](\mathrm{OTf})_{3}$ viewed along the crystallographic a axis; crystallographic axes of the unit cell are shown, solvent molecules are omitted. 
Table 3 Selected bond lengths and angles of trinuclear complexes $\left[(1 \mathrm{a})_{2}(\mathrm{Au})_{3}\right](\mathrm{OTf})_{3},\left[(1 \mathrm{~b})_{2}(\mathrm{Au})_{3}\right](\mathrm{OTf})_{3}$, and polymeric $\left\{\left[(1 \mathrm{c})_{2}(\mathrm{Au})_{3}\right](\mathrm{OTf})_{3}\right\}_{n}$, numbering of $\mathrm{P}$ atoms according to Fig. 2 and 6

\begin{tabular}{|c|c|c|c|c|}
\hline & & $\begin{array}{l}{\left[(\mathbf{1 a})_{2}(\mathrm{Au})_{3}\right]} \\
(\mathrm{OTf})_{3}\end{array}$ & $\begin{array}{l}{\left[(\mathbf{1 b})_{2}(\mathrm{Au})_{3}\right]} \\
(\mathrm{OTf})_{3}\end{array}$ & $\begin{array}{l}\left\{\left[(\mathbf{1 c})_{2}(\mathrm{Au})_{3}\right]\right. \\
\left.(\mathbf{O T f})_{3}\right\}_{\mathbf{n}}\end{array}$ \\
\hline \multirow{6}{*}{$\mathrm{Au}(\mathrm{m})-\mathrm{P}[\mathrm{A}]$} & \multirow[t]{2}{*}{$\operatorname{Au}(1)$} & $2.301(2)$ & $2.295(2)$ & $2.303(1)$ \\
\hline & & $2.302(2)$ & $2.298(2)$ & $2.304(1)$ \\
\hline & \multirow{2}{*}{$\mathrm{Au}(2)$} & $2.303(2)$ & $2.299(2)$ & $2.305(3)$ \\
\hline & & $2.303(2)$ & $2.298(2)$ & $2.320(3)$ \\
\hline & \multirow[t]{2}{*}{$\mathrm{Au}(3)$} & $2.302(3)$ & $2.302(2)$ & $2.296(1)$ \\
\hline & & $2.304(3)$ & $2.300(1)$ & $2.299(1)$ \\
\hline \multirow[t]{3}{*}{$\mathrm{P}-\mathrm{Au}(\mathrm{m})-\mathrm{P}\left[^{\circ}\right]$} & $\mathrm{Au}(1)$ & $171.96(8)$ & $173.33(6)$ & $170.45(5)$ \\
\hline & $\mathrm{Au}(2)$ & 164.05(8) & $162.44(7)$ & 171.4(1) \\
\hline & $\mathrm{Au}(3)$ & $162.92(8)$ & $164.85(6)$ & $172.72(5)$ \\
\hline
\end{tabular}

of $\left[(\mathbf{1 a})_{2}(\mathrm{Au})_{3}\right](\mathrm{OTf})_{3}$ could be modelled, showing a weak $\mathrm{Au}(1) \cdots \mathrm{O}(1)$ contact $(3.46(2) \AA)$. The presence of three triflate anions per trication is, however, confirmed by ${ }^{19} \mathrm{~F}\left\{{ }^{1} \mathrm{H}\right\}$ NMR spectroscopy and CHN analysis. Additionally, the larger channels (approx. $6.8 \AA \times 9.9 \AA$ ) are filled with heavily disordered solvent molecules. In line with the solvent stabilising the porous structure, drying the crystalline materials obtained from $\mathrm{CH}_{2} \mathrm{Cl}_{2}$ /toluene under reduced pressure leads to a visible and sudden loss of crystallinity, leaving fine powders after drying.

The discrete trinuclear complexes can be understood as a blend of mononuclear $[\mathbf{1 b}(\mathbf{A u})] \mathbf{O T f}$ and CP $\left\{\left[(\mathbf{1 c})_{2}(\mathbf{A u})_{3}\right](\mathbf{O T f})_{3}\right\}_{n}$, particularly regarding the $\mathrm{P}-\mathrm{Au}-\mathrm{P}$ bond angles which, for the central gold(I) ion, are closer to the ideal $180^{\circ}$ than for the outer gold(I) ions (Tables 3 and S3†). $\left[(\mathbf{1 a})_{2}(\mathbf{A u})_{3}\right](\mathbf{O T f})_{3}$ and $\left[(\mathbf{1 b})_{2}(\mathbf{A u})_{3}\right](\mathbf{O T f})_{3}$ maintain their structure in $\mathrm{CD}_{2} \mathrm{Cl}_{2}$ solution as evident from HR-ESI mass spectrometry through signals for the tricationic species, and from ${ }^{1} \mathrm{H}$ and ${ }^{31} \mathrm{P}\left\{{ }^{1} \mathrm{H}\right\}$ NMR spectroscopy (Fig. S15ff $\dagger$ ). The two distinct ${ }^{31} \mathrm{P}\left\{{ }^{1} \mathrm{H}\right\}$ resonances also demonstrate the influence of the $\mathrm{P}-\mathrm{Au}-\mathrm{P}$ bond angle on the exact chemical shift - more acute angles result in a slight deshielding.

These results corroborate the decisive role of the arene core constituent $\mathbf{E}$ and, as demonstrated for $\mathbf{1} \mathbf{a}^{\mathbf{F}}$, the role of the $P$-bound substituents in determining the coordination mode of the tris-phosphanes towards gold(I) as schematically summarised in Fig. 7.

\section{Electrochemistry and redox-switchable catalysis}

As trinuclear chloridogold(I) complexes of 1a-c have shown high potential for multi-state redox-switchable catalysis due to their stepwise, well-separated, and reversible trifold oxidation, ${ }^{36}$ the electrochemical and, following, catalytic characterisation of the previously described gold(I) complexes were also of interest. The electrochemistry of tris-phosphanes 1a-c and $[\mathbf{1 a}(\mathbf{A u})] \mathbf{O T f}$ has already been studied, ${ }^{35,36}$ and $[\mathbf{1} \mathbf{a}(\mathbf{A u})] \mathbf{O T f}$ in particular has shown unexpected behaviour involving chemical follow-up reactions induced by electrochemical oxidation (EC mechanism). Because the isolation of sufficient amounts of pure $[\mathbf{1 c}(\mathbf{A u})]$ oTf had not been successful and since the $\mathrm{CP}\left\{\left[(\mathbf{1 c})_{2}(\mathbf{A u})_{3}\right](\mathbf{O T f})_{3}\right\}_{n}$ is likely ill-defined in solution, we

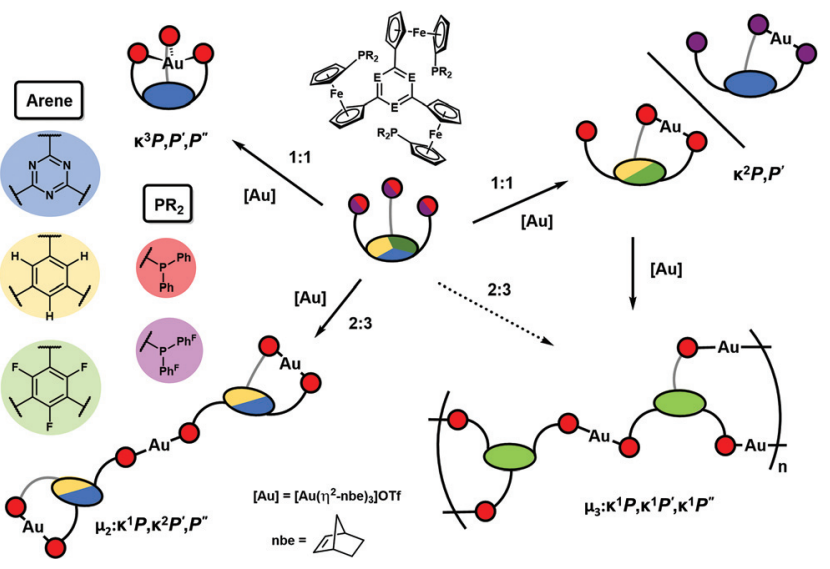

Fig. 7 Schematic depiction of the different coordination modes observed for tris-phosphanes $1 \mathrm{a}-\mathrm{c}$ and $1 \mathrm{a}^{\mathrm{F}}$ depending on the arene core constituent $\mathrm{E}$ and on the phosphanyl moiety $\mathbf{P R}_{\mathbf{2}}$. For clarity, charges and triflate anions have been omitted from the depicted structures. The dashed arrow represents the indirect access to the coordination polymer from $1 c$.

first focused on well-defined $[\mathbf{1 b}(\mathbf{A u})] \mathbf{O T f},\left[(\mathbf{1 b})_{2}(\mathbf{A u})_{3}\right](\mathbf{O T f})_{3}$, and $\left[(\mathbf{1 a})_{2}(\mathbf{A u})_{3}\right](\mathbf{O T f})_{3}$ in $\mathrm{BF}_{4}{ }^{--}$and tetrakis[3,5-bis(trifluoromethylphenyl)]borate-based $\left(\mathrm{BAr}_{4}{ }^{-}\right)$supporting electrolytes (SE). The corresponding cyclic voltammograms are shown in Fig. 8.

Quite unexpectedly, given the pendant diphenylphosphane group of $[\mathbf{1 b}(\mathbf{A u})]$ OTf and the well-documented involvement of

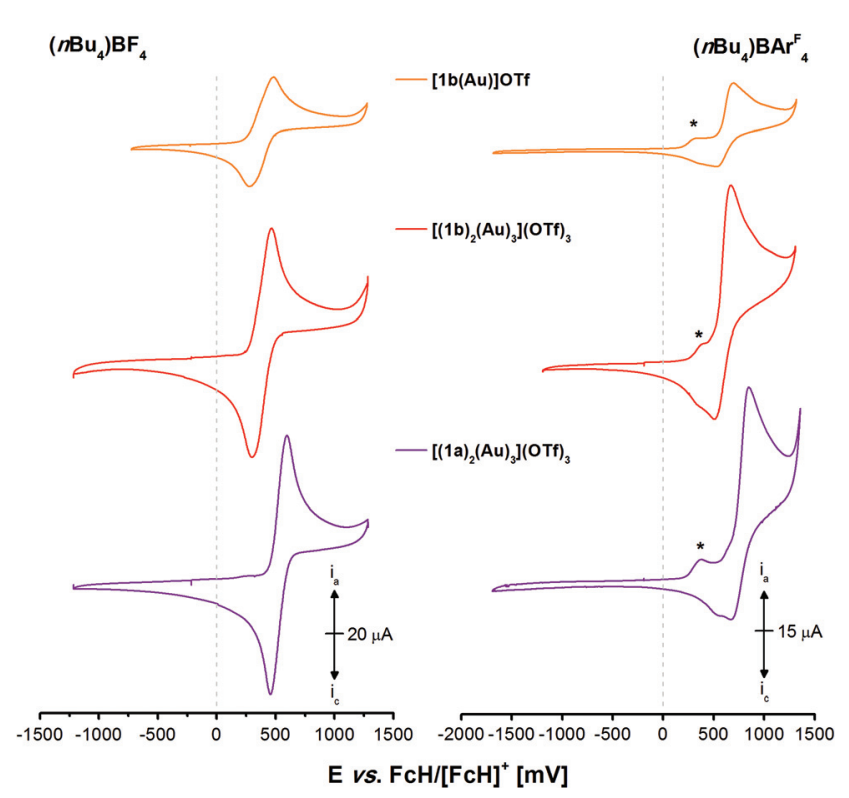

Fig. 8 Cyclic voltammograms of $1 \mathrm{mmol} \mathrm{L}^{-1}$ gold(I) complexes [1b(Au)]OTf (orange), $\left[(1 \mathrm{~b})_{2}(\mathrm{Au})_{3}\right](\mathrm{OTf})_{3}$ (red), and $\left[(1 \mathrm{a})_{2}(\mathrm{Au})_{3}\right](\mathrm{OTf})_{3}$ (purple) in $0.1 \mathrm{~mol} \mathrm{~L}^{-1}$ supporting electrolyte solutions $\left(\left(n \mathrm{Bu}_{4} \mathrm{~N}\right) \mathrm{BF}_{4}\right.$ (left) and $\left(n \mathrm{Bu}_{4} \mathrm{~N}\right) \mathrm{BAr}_{4}{ }_{4}$ (right) in $\mathrm{CH}_{2} \mathrm{Cl}_{2}$ ). Traces have been recorded at $100 \mathrm{mV} \mathrm{s}^{-1}$ (working electrode: glassy carbon, counter electrode: $\mathrm{Pt}$ wire) at room temperature. The first oxidations ${ }^{*}$ ) in the $\mathrm{BAr}^{\mathrm{F}}$-based SE are irreversible when addressed separately. The second of three measured cycles are shown. 
free phosphorus-centred lone pairs of electrons in ferrocene oxidation, ${ }^{113-116}$ the oxidation of [1b(Au)]OTf (orange trace) in the $\mathrm{BF}_{4}$-based $\mathrm{SE}$ (Fig. 8, left) was found quasireversible ( $c f$. section 5.1 of the ESI $\dagger$ ). ${ }^{117,118}$ Assuming that the fluctional coordination behaviour observed in the VT NMR experiments renders all three ferrocenylene moieties equivalent on the cyclic voltammetry timescale and hence not bearing lone pairs of electrons available for follow-up chemistry, all three ferrocenylene groups are most likely oxidised at the same potential. Similar behaviour has been reported for 1,3,5-tris(ferrocenyl)benzene $^{37,119}$ and its 1,1'-substituted derivatives, yet not for free 1b itself. $^{36}$ Further support comes from hexa-ferrocene derivatives $\left[(\mathbf{1 b})_{2}(\mathbf{A u})_{3}\right](\mathbf{O T f})_{3}\left(\right.$ red trace) and $\left[(\mathbf{1 a})_{2}(\mathbf{A u})_{3}\right](\mathbf{O T f})_{3}$ (purple trace) which also yield one quasireversible redox event under the same conditions, as all phosphanes are permanently involved in gold(I) coordination. Twice-as-high currents $i_{\mathrm{a} / \mathrm{c}}$ suggest the simultaneous oxidation of all six ferrocenylene groups. The decisive role of the high mobility and of the potential to form tight ion pairs of the $\mathrm{BF}_{4}{ }^{-}$anions becomes apparent when the SE is changed to the much more weakly coordinating $\mathrm{BAr}_{4}^{\mathrm{F}}{ }^{-}$anions (Fig. 8, right). ${ }^{120}$ The oxidations of all three complexes follow the same pattern of a low-current, irreversible first oxidation (*) followed by a much stronger second, also not fully reversible, oxidation event (for corresponding potentials, $c f$. Table 4). On reversing the scan direction, two close-spaced reductions take place, less reversible for the triazine than for the benzene core. In general and in line with our expectations, the less electron-rich triazine leads to appreciably higher oxidation/reduction potentials for its gold(I) complex (with the notable exception for the weak first oxidation $\left(^{*}\right)$ ), while the similar coordination modes of all complexes result in overall very similar electrochemical characteristics.

The electrochemistry of $\mathbf{1} \mathbf{a}^{\mathbf{F}}$ and the two mononuclear com-

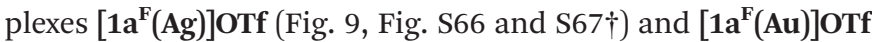
(Fig. S68, $\dagger$ measured at a lower concentration due to a limited amount of available material; all potentials in Table S6†) is, in contrast, very different from that of their non-fluorinated counterparts. Free $\mathbf{1 a}^{\mathbf{F}}$ (light green) can be reversibly oxidised in three well-separated steps in the $\mathrm{BAr}^{\mathrm{F}}{ }_{4}$-based $\mathrm{SE}$ (1a-c only feature a first reversible oxidation and need to be protected by $\mathrm{BH}_{3}$ groups to see the same pattern), ${ }^{36}$ in line with reports for dppf derivative VII (Chart 3) by the Gusev group. ${ }^{98}$ Gusev and

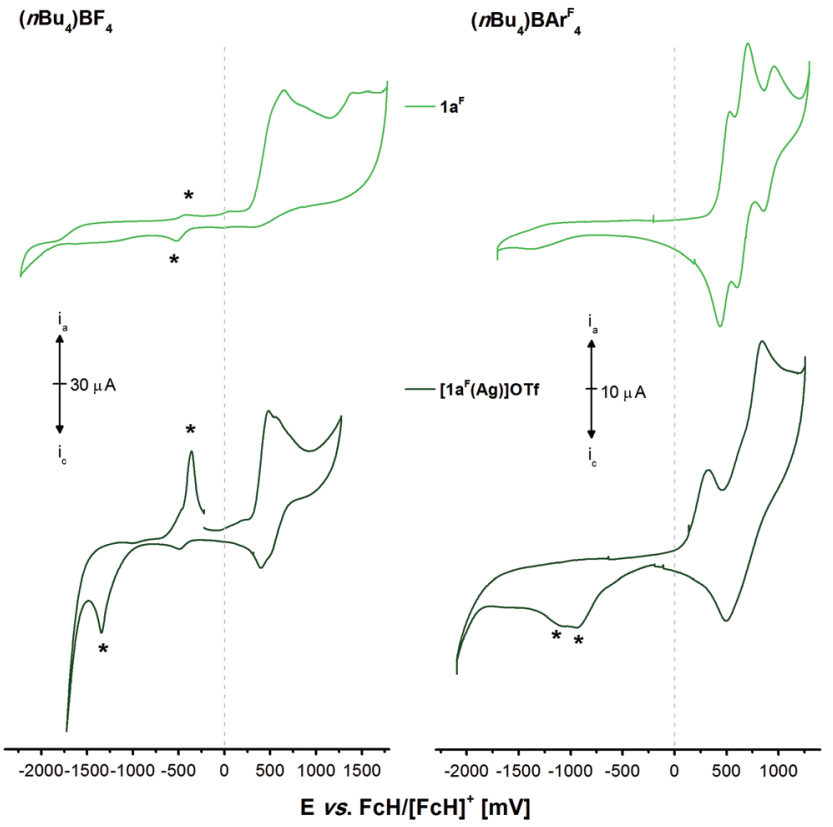

Fig. 9 Cyclic voltammograms of $1 \mathrm{mmol} \mathrm{L}^{-1} 1 \mathrm{a}^{\mathrm{F}}$ (light green) and $\left[1 \mathrm{a}^{\mathrm{F}}(\mathrm{Ag})\right] \mathrm{OTf}$ (dark green) in $0.1 \mathrm{~mol} \mathrm{~L}^{-1}$ supporting electrolyte solutions $\left(\left(n \mathrm{Bu}_{4} \mathrm{~N}\right) \mathrm{BF}_{4}\right.$ (left) and $\left(n \mathrm{Bu}_{4} \mathrm{~N}\right) \mathrm{BAr}_{4}{ }_{4}$ (right) in $\left.\mathrm{CH}_{2} \mathrm{Cl}_{2}\right)$. Traces have been recorded at $100 \mathrm{mV} \mathrm{s}^{-1}$ (working electrode: glassy carbon, counter electrode: Pt wire) at room temperature. The second of three cycles are shown and asterisks (*) mark oxidation/reduction events which depend on prior oxidation in the first cycle (cf. Fig. S66 and S67†).

co-workers speculated that this reversibility originated from steric protection of potential $P$-centred radicals from dimerisation. While the steric demand of fluorine is indeed greater than that of hydrogen, ${ }^{85}$ we believe the lowered energy of the lone pair of electrons at the $\mathrm{P}$ atoms to be a more likely explanation. ${ }^{113,114,116,121,122}$ Accordingly, the Mulliken spin densities of monocations $[\mathbf{1 a}]^{+}$and $\left[\mathbf{1 a}^{\mathbf{F}}\right]^{+}$calculated at the DFT level are distributed differently, with $\left[\mathbf{1 a}^{\mathrm{F}}\right]^{+}$showing a four times greater spin density (0.012) summed up over all three $\mathrm{P}$ atoms than $[\mathbf{1 a}]^{+}(0.003)$. In the $\mathrm{BF}_{4}$-based $\mathrm{SE}$, the oxidations are not reversible anymore, and much like for 1a, the first oxidation induced a delayed reduction.

In the $\mathrm{BF}_{4}$-based $\mathrm{SE}$, neither the two complexes nor free $\mathbf{1 a}^{\mathbf{F}}$ are reversibly oxidisable, and all compounds show oxidationinduced delayed reductions (and re-oxidations; Fig. 8, *). This

Table 4 Redox potentials ${ }^{a} E^{0}$, oxidation $E^{\text {ox }}$, and reduction $E^{\text {red }}$ peak potentials of the gold(I) complexes in two different supporting electrolytes determined by cyclic voltammetry

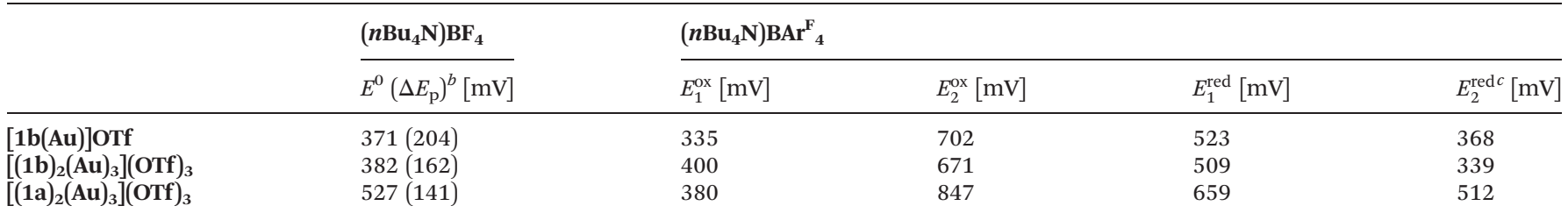

${ }^{a}$ All potentials reported $v s$. the $\mathrm{FcH} /[\mathrm{FcH}]^{+}$couple at a glassy carbon working electrode (scan rate $100 \mathrm{mV} \mathrm{s}^{-1}$ ) in anhydrous supporting electrolytes, measured under a blanket of nitrogen. ${ }^{b}$ Splitting between the anodic (oxidation) and cathodic (reduction) peaks. ${ }^{c}$ Shoulder in cyclic voltammograms of $[\mathbf{1 b}(\mathbf{A u})]$ OTf and $\left[(\mathbf{1 b})_{2}(\mathbf{A u})_{3}\right](\mathbf{O T f})_{3}$. 
behaviour has previously been observed for 1a and its coinage metal complexes as well. A higher degree of reversibility is observed in the $\mathrm{BAr}^{\mathrm{F}}{ }_{4}$-based SE; yet, similar to $[\mathbf{1} \mathbf{b}(\mathbf{A u})] \mathbf{O T f}$, the oxidations are not completely reversible and, in the case of $\left[\mathbf{1 a}^{\mathbf{F}}(\mathbf{A g})\right] \mathbf{O T f}$, delayed reductions are observed again. Given their complex redox chemistry and unsatisfactory yields and purity, $\left[\mathbf{1 a}^{\mathbf{F}}(\mathbf{A g})\right] \mathbf{O T f}$ and $\left[\mathbf{1 a}^{\mathbf{F}}(\mathbf{A u})\right] \mathbf{O T f}$ were not considered for the following redox-switchable catalysis (RSC) investigations.

As a suitable model reaction for testing the previously presented mono- and trinuclear complexes in RSC, the ringclosing isomerisation of propargylic amide 2 to oxazoline $\mathbf{3 a}$ (Scheme 1) 18,123-126 was studied by time-resolved ${ }^{1} \mathrm{H}$ NMR spectroscopy $v s$. an internal standard (1,3,5-trimethoxybenzene) in $\mathrm{CD}_{2} \mathrm{Cl}_{2}$. While trinuclear chloridogold(I) complexes of 1a-c exclusively yielded $\mathbf{3 a}$ with an exocyclic methylene group, ${ }^{36}$ other (redox-switchable) gold(I/III) catalysts are known to also catalyse the aromatisation of $\mathbf{3 a}$ to oxazole $\mathbf{3 b}$ in a subsequent step. ${ }^{51,127}$

$[\mathbf{1 a}(\mathbf{A u})]$ OTf - which had not yet been tested in catalysis and $[\mathbf{1 b}(\mathbf{A u})] \mathbf{O T f}$, at a concentration of $3 \mathrm{~mol} \%$ gold(I) with respect to 2 , were found to be catalytically inactive (Fig. 10, phase i). Most likely, steric hindrance arising from the $\kappa^{3} P, P^{\prime}, P^{\prime \prime}$ coordination mode in $[\mathbf{1 a}(\mathbf{A u})]$ OTf prevents the substrate from approaching the cationic gold(I) centre which otherwise would be expected to show some, albeit low, activity (vide infra). Given the fluctional coordination behaviour of $[\mathbf{1 a}(\mathbf{A u})]$ OTf and the resulting apparent $C_{3 \mathrm{v}}$-symmetric tricoordinate geometry on the NMR time scale, the substrate might be unable to approach the gold(I) ion on the catalytic time scale, too. Attempting to rationalise this assumption, the buried volume $\% V_{\text {bur }}$, a measure for the steric bulk of a ligand at and around the coordinated metal originally developed for $\mathrm{N}$-heterocyclic carbenes, ${ }^{128,129}$ was calculated for both coordination modes (bi- and tridentate). Based on the available solid-state structures and using the SambVca web application by Cavallo and co-workers, ${ }^{130}$ the $C_{3}$-symmetric coordination of the three phosphanes results in a $\% V_{\text {bur }}$ of almost $90 \%$, while the bidentate bonding mode in $[\mathbf{1 b}(\mathbf{A u})]$ OTf corresponds

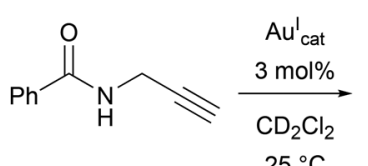

2

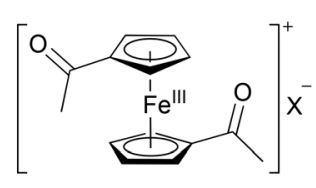

$5 \mathbf{a}(X=\mathrm{TEF})$

5b $\left(X=\mathrm{BF}_{4}\right)$

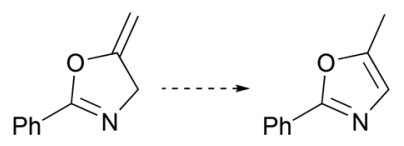

$3 a$

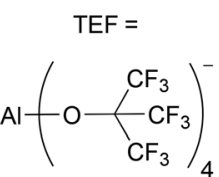

$\mathrm{F}_{4}$

(1)

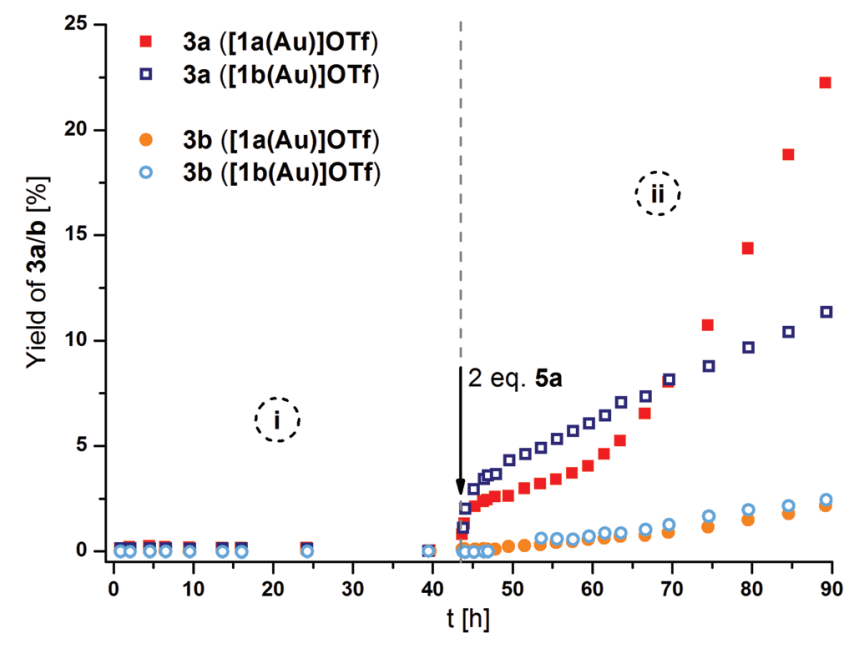

Fig. 10 Reaction profiles for ring-closing isomerisation of 2 to $3 a$ (squares) by $[1 \mathrm{a}(\mathrm{Au})] \mathrm{OTf}$ (solid symbols) and [1b(Au)]OTf (hollow symbols), also showing the formation of the aromatic follow-up product $3 \mathrm{~b}$ (circles) before (i) and after (ii) oxidation with 2 eq. 5a (with respect to catalyst; 3 mol\% Au, [2] $\left.]_{0}=60 \mathrm{mmol} \mathrm{L}^{-1}, \mathrm{CD}_{2} \mathrm{Cl}_{2}, 25^{\circ} \mathrm{C}\right)$. For corresponding ${ }^{1} \mathrm{H}$ NMR spectra and TOF regression plots, s. Fig. S73, S75, and S76.†

to a significantly smaller $\% V_{\text {bur }}$ of about $67 \%$ ( $c f$. ESI, section $7.2 \dagger)$. Due to the fast coordination-dissociation equilibrium of $[\mathbf{1 b}(\mathbf{A u})] \mathbf{O T f}$, the effective buried volume in solution is likely closer to the $90 \%$ of $[\mathbf{1 a ( A u )}] \mathbf{O T f}$.

In line with the room-temperature oxidation of $[\mathbf{1 a}(\mathbf{A u})] \mathbf{O T f}$ following a two-electron-process, ${ }^{35} 2$ eq. of oxidant $\mathbf{5 a}$ (Scheme 1), containing the very weakly coordinating teflonate anion (tetrakis(tert-butoxy)aluminate, TEF), ${ }^{131,132}$ were added to the respective reaction mixtures. While the conversion of 2 to 3a (Fig. 10, squares) was indeed initiated upon oxidation (phase ii), the resulting catalytic activities as expressed by the turn-over-frequencies (TOF) were very low ([1a(Au)]OTf: $0.79 \pm 0.02 \mathrm{~h}^{-1} ;[\mathbf{1 b}(\mathbf{A u})] \mathbf{O T f}: 0.18 \pm 0.01 \mathrm{~h}^{-1}, c f$. Table $\mathrm{S} 7$ and Fig. S75, S76†). Next to unusual reaction profiles - a steep initial increase followed by a flattening for $[\mathbf{1 b}(\mathbf{A u})] \mathbf{O T f}$ and an inverse-sigmoidal progression for $[\mathbf{1 a}(\mathbf{A u})] \mathbf{O T f}$ - both catalytic runs also produced detectable amounts of aromatic follow-up product 3b (Fig. 10, spheres).

The fate of $[\mathbf{1 a}(\mathbf{A u})]$ OTf upon oxidation had already been studied in some detail and was revealed to involve electron transfer from $\mathrm{P}$ to $\mathrm{Fe}^{\mathrm{III}}$ after an initial iron(II)-centred oxidation, leading to the formation of a phosphane oxide species due to adventitious traces of water. ${ }^{35}$ Oxidation-induced reactivity, potentially involving substrate 2 and generating new, catalytically active species, is thus quite likely in this case, too.

The stepwise oxidation of $[\mathbf{1} \mathbf{b}(\mathbf{A u})]$ OTf with $\mathbf{5 a}$ in $\mathrm{CD}_{2} \mathrm{Cl}_{2}$ was followed by a multinuclear NMR experiment, including the attempted reduction with decamethylferrocene (6) (Fig. S92-S94†). The appearance of several ${ }^{31} \mathrm{P}\left\{{ }^{1} \mathrm{H}\right\}$ signals centred at about $43 \mathrm{ppm}$ with small but noticeable changes between the addition of one and two equivalents of $\mathbf{5 a}$ indicates the generation of $P, P^{\prime}$-dicoordinate species. Regeneration 
of $[\mathbf{1 b}(\mathbf{A u})]$ OTf by addition of $\mathbf{6}$ was not observed in neither the ${ }^{1} \mathrm{H}$ nor the ${ }^{31} \mathrm{P}\left\{{ }^{1} \mathrm{H}\right\}$ NMR spectra, even though crystalline [6](TEF) was isolated from the reaction mixture after work-up. Furthermore, the ${ }^{19} \mathrm{~F}\left\{{ }^{1} \mathrm{H}\right\}$ NMR signal of the triflate anion is strongly broadened suggesting its involvement in the follow-up chemistry. Spectroelectrochemical (SEC) measurements in the $\mathrm{BAr}_{4}^{\mathrm{F}}$-based SE at $25{ }^{\circ} \mathrm{C},-50{ }^{\circ} \mathrm{C}$, and $-80{ }^{\circ} \mathrm{C}$ (Fig. S69 and S70 $\dagger$ ), contrasting the cyclic voltammetry experiments in the same SE, showed good reversibility of the likely $\mathrm{Fe}^{\mathrm{II}}$-centred first oxidation and a less reversible second oxidation at $25{ }^{\circ} \mathrm{C}$ which became more reversible at $-50{ }^{\circ} \mathrm{C}$. All taken together, these partly conflicting and complex observations disqualify [1a(Au)]OTf and [1b(Au)]OTf for further applications in RSC.

We thus focused our attention on the tri-gold, hexaferrocene complexes $\left[(\mathbf{1 a})_{2}(\mathbf{A u})_{3}\right](\mathbf{O T f})_{3}$ and $\left[(\mathbf{1 b})_{2}(\mathbf{A u})_{3}\right](\mathbf{O T f})_{3}$, expecting them to show a more predictable and rewarding catalytic profile. The buried volumes $\% \mathrm{Vol}_{\text {bur }}$ for the central (73\%) and peripheral (66\%, cf. section 7.2 of the ESI $\dagger$ ) gold(I) centres are similar to that of $[\mathbf{1} \mathbf{b}(\mathbf{A u})] \mathbf{O T f}$ and likely profit from the fixed coordination geometry (i.e., no pendant phosphane group). Indeed, both complexes displayed low but discernible catalytic activity in their native states (Fig. 11, top, hollow symbols). At this low activity level (phase iii), the TOF of both catalysts are similar and, over long time periods (native species), virtually identical ( $c f$. Table $\mathrm{S} 7 \dagger$ ).

Upon addition of two equivalents of $\mathbf{5 a}$ (phase iv), an immediate increase in activity took place $\left(\left[(\mathbf{1 a})_{2}(\mathbf{A u})_{3}\right](\mathbf{O T f})_{3}+2\right.$ 5a: $10.7 \times,\left[(\mathbf{1 b})_{2}(\mathbf{A u})_{3}\right](\mathbf{O T f})_{3}+2$ 5a: 12.3×), triazine-based $\left[(\mathbf{1 a})_{2}(\mathbf{A u})_{3}\right](\mathbf{O T f})_{3} \quad(+2 \quad 5 \mathbf{5 a})$ clearly outperforming $(\mathrm{TOF}=$ $\left.4.2 \pm 0.1 \mathrm{~h}^{-1}\right)$ benzene-based $\left[(\mathbf{1 b})_{2}(\mathbf{A u})_{3}\right](\mathbf{O T f})_{3}(+2 \mathbf{5 a})(\mathrm{TOF}=$

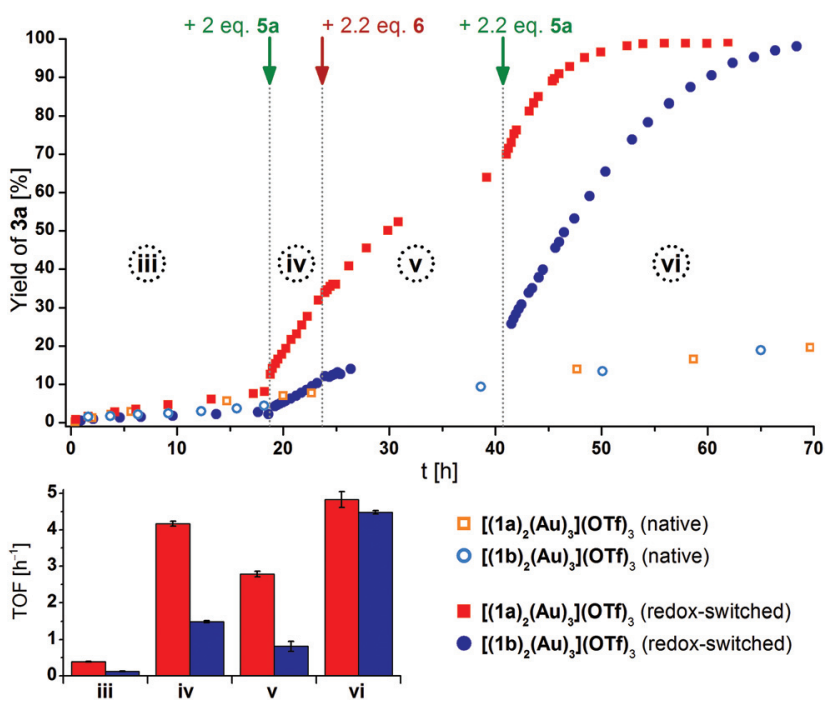

Fig. 11 Top: Reaction profiles for ring-closing isomerisation of 2 to $3 a$ by $\left[(1 \mathrm{a})_{2}(\mathrm{Au})_{3}\right](\mathrm{OTf})_{3}$ (squares) and $\left[(\mathrm{lb})_{2}(\mathrm{Au})_{3}\right](\mathrm{OTf})_{3}$ (circles) in native (hollow) and oxidised/reduced (solid) state $\left(3 \mathrm{~mol} \% \mathrm{Au},[2]_{0}=60 \mathrm{mmol} \mathrm{L}{ }^{-1}\right.$, $\mathrm{CD}_{2} \mathrm{Cl}_{2}, 25^{\circ} \mathrm{C}$ ). Arrows indicate the addition of additives for the redoxswitched traces. Bottom: Comparison of turn-over frequencies (TOF) determined from linear fits (For corresponding ${ }^{1} \mathrm{H}$ NMR spectra and TOF regression plots, s. Fig. S74 and S77-80†) referring to reaction phases iii-iv. $\left.1.5 \pm 0.1 \mathrm{~h}^{-1}\right)$. As the increased activity is usually explained based on the increase in the Lewis acidity of gold(I) through oxidation of iron(II) to iron(III), ${ }^{18,124,127,133}$ reduction of the presumed ferrocenium species should regenerate the initial low activity. Thus, 2.2 equivalents of 6 were added to the reaction mixtures (phase v). In both cases, the TOF moderately decreased $\left(\left[(\mathbf{1 a})_{2}(\mathbf{A u})_{3}\right](\mathbf{O T f})_{3}+2 \mathbf{5 a}+2.2\right.$ 6: $0.67 \times$, $\left[(\mathbf{1 b})_{2}(\mathbf{A u})_{3}\right](\mathbf{O T f})_{3}+25 \mathbf{5 a}+2.2$ 6: $\left.0.55 \times\right)$, yet without fully returning to the initial low activities. ${ }^{134}$ When 2.2 equivalents of $5 \mathbf{a}$ were added (phase vi), the activity of re-oxidised $\left[(\mathbf{1 a})_{2}(\mathbf{A u})_{3}\right](\mathbf{O T f})_{3}$ slightly surpassed the pre-reduction value by a factor of 1.1 , while re-oxidised $\left[(\mathbf{1 b})_{2}(\mathbf{A u})_{3}\right](\mathbf{O T f})_{3}$ showed a 3 -fold increase of TOF with respect to phase iv.

To gain more insight into the redox-switching behaviour, SEC measurements of $\left[(\mathbf{1 a})_{2}(\mathbf{A u})_{3}\right](\mathbf{O T f})_{3}$ and $\left[(\mathbf{1 b})_{2}(\mathbf{A u})_{3}\right](\mathbf{O T f})_{3}$ in the $\mathrm{BAr}^{\mathrm{F}}{ }_{4}$-based SE were conducted (Fig. 12 and S71, S72 $\dagger$ ), the $\mathrm{BAr}^{\mathrm{F}}{ }_{4}^{-}$anion being a suitable substitute for the teflonate anion concerning its low ion-pairing properties and inertness. $^{132}$ In some contrast to the results from the $\mathrm{CV}$ (vide supra), the oxidation of $\left[(\mathbf{1 b})_{2}(\mathbf{A u})_{3}\right](\mathbf{O T f})_{3}$ (Fig. 12, left) was found to be fully reversible under these conditions, even though the reduction potential had to be applied for an extended time. The UV/Vis signature relates to an iron-centred oxidation, ${ }^{135-137}$ and the broad band centred at about $820 \mathrm{~nm}$ likely relates to a ligand-to-metal charge transfer between the cyclopentadienyl rings and iron(III). ${ }^{37}$ When $\left[(\mathbf{1 a})_{2}(\mathbf{A u})_{3}\right](\mathbf{O T f})_{3}$ is oxidised at potentials greater than $1 \mathrm{~V}\left(v s . \mathrm{FcH} /[\mathrm{FcH}]^{+}\right.$, Fig. 12 top right), the intensely purple species formed cannot

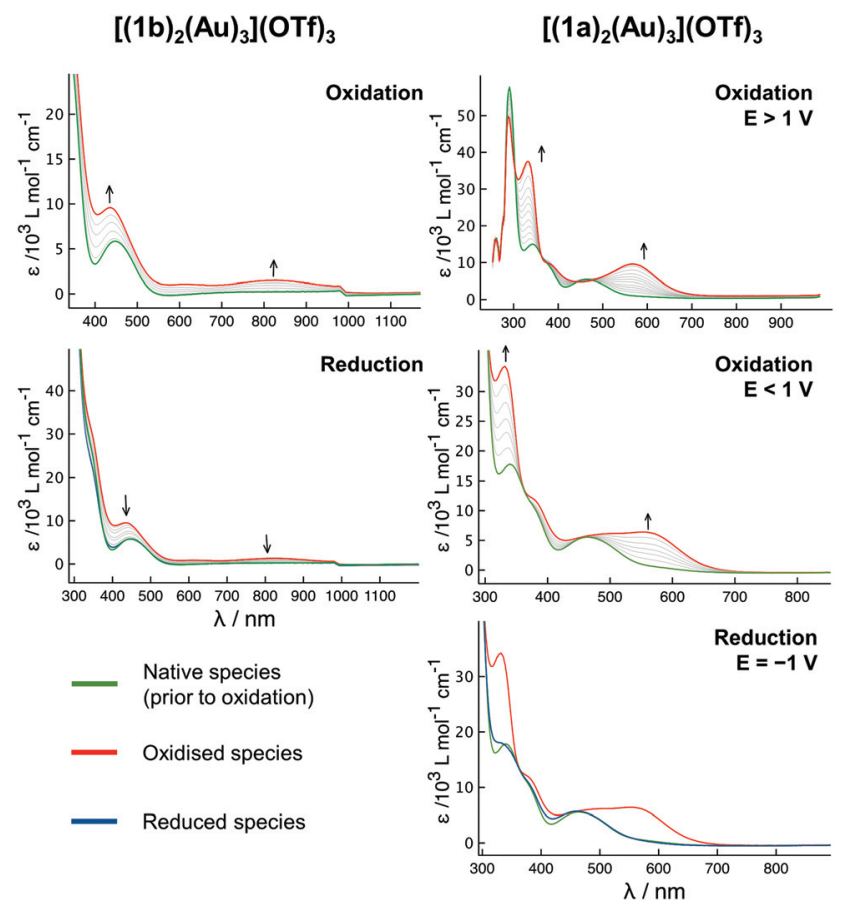

Fig. 12 Plots obtained from UV/Vis spectroelectrochemical measurements of $\left[(1 \mathrm{a})_{2}(\mathrm{Au})_{3}\right](\mathrm{OTf})_{3}$ (right) and $\left[(1 \mathrm{~b})_{2}(\mathrm{Au})_{3}\right](\mathrm{OTf})_{3}$ (left) in $0.1 \mathrm{~mol} \mathrm{~L}^{-1}$ $\left(n \mathrm{Bu}_{4} \mathrm{~N}\right) \mathrm{BAr}_{4}$ in $\mathrm{CH}_{2} \mathrm{Cl}_{2}$ at $25^{\circ} \mathrm{C}$. Arrows highlight the position and direction of evolving/disappearing peaks. 
be reduced anymore, while oxidation below $1 \mathrm{~V}$ leads to a slightly different UV/Vis trace and allows for a reduction, however requiring a cathodic potential of $-1 \mathrm{~V}$. In both cases, the UV/Vis spectrum obtained after oxidation strongly resembles that obtained from oxidising $[\mathbf{1 a}(\mathbf{A u})]$ OTf in the same SE, a process which was found to generate very reactive species from intramolecular electron transfer after an initial iron-centred oxidation. ${ }^{35}$ Following the oxidation of $\left[(\mathbf{1 a})_{2}(\mathbf{A u})_{3}\right](\mathbf{O T f})_{3}$ with two equivalents of $\mathbf{5 a}$ by multinuclear NMR spectroscopy (Fig. S95†), good yet delayed reducibility by 2.2 equivalents of $\mathbf{6}$ was observed. Using $\mathrm{BF}_{4}$-based oxidant $\mathbf{5 b}$ in the same stoichiometric ratio (Fig. S96†), a different spectral fingerprint was observed, and addition of 6 did not regenerate the initial spectral features. Treating $\left[(\mathbf{1 b})_{2}(\mathbf{A u})_{3}\right](\mathbf{O T f})_{3}$ with two equivalents of $\mathbf{5 b}$ (Fig. S97 $\dagger$ ), full reversibility upon addition of $\mathbf{6}$ was found. Studying $\mathbf{5 b}$ as a substitute for $5 \mathbf{a}$ - anions are known to play important roles in gold(I) catalysis $^{89,138,139}$ - was, however, complicated by its poor solubility in $\mathrm{CH}_{2} \mathrm{Cl}_{2} / \mathrm{CD}_{2} \mathrm{Cl}_{2}$, as exact dosing of the required small amounts was found to be impossible.

Owing to its more attractive redox features, especially as observed in SEC, a series of catalytic runs in which $\left[(\mathbf{1 b})_{2}(\mathbf{A u})_{3}\right](\mathbf{O T f})_{3}$ was oxidised by one to six equivalents of $\mathbf{5 a}$ was conducted (Fig. 13). When left oxidised, the doubly oxidised species (light green hollow circles) performs with a TOF of $5.4 \pm 0.1 \mathrm{~h}^{-1}(32.6-41.0 \mathrm{~h})$, similar to the TOF of $4.5 \pm 0.1 \mathrm{~h}^{-1}$ observed after re-oxidation in the previous experi-

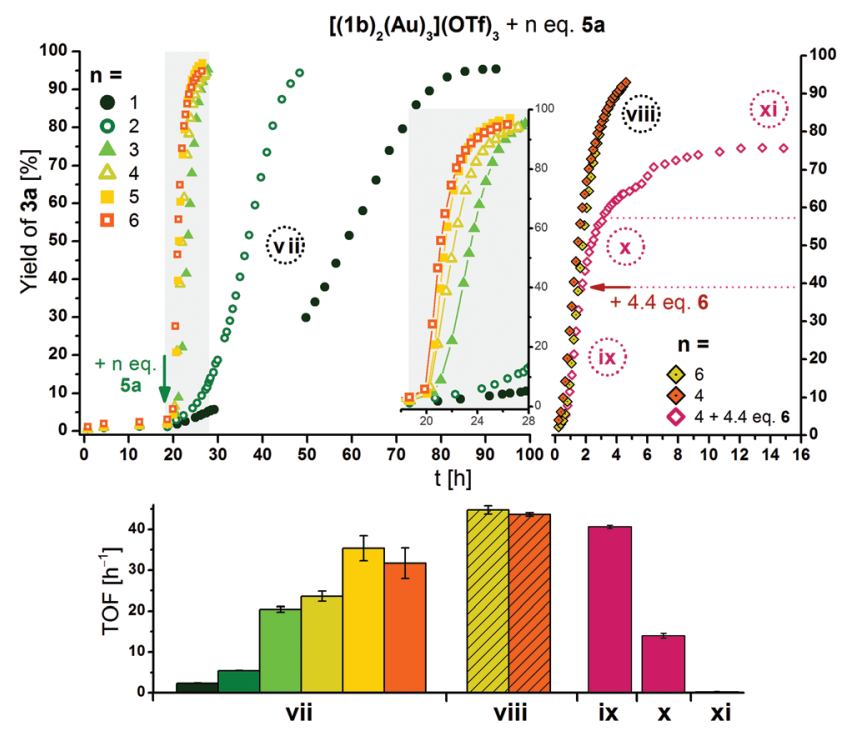

Fig. 13 Top left: Reaction profiles for ring-closing isomerisation of 2 to $3 a$ by $\left[(1 \mathrm{~b})_{2}(\mathrm{Au})_{3}\right](\mathrm{OTf})_{3}\left(3 \mathrm{~mol} \% \mathrm{Au},[2]_{0}=60 \mathrm{mmol} \mathrm{L}-1, \mathrm{CD}_{2} \mathrm{Cl}_{2}, 25^{\circ} \mathrm{C}\right)$ oxidised by $1-6$ eq. of $5 a$ at the indicated time (arrow). The insert shows a magnified time period, and lines connecting the symbols are for visual guidance only. Top right: Reaction profiles for ring-closing isomerisation of 2 to $3 a$ by $\left[(1 b)_{2}(\mathrm{Au})_{3}\right](\mathrm{OTf})_{3}$ (conditions as above), oxidised by four (orange/grape) and six (mustard) eq. of 5 a directly before the start of the ${ }^{1} \mathrm{H}$ NMR monitoring (viii). To one run (grape), 4.4 eq. of reductant 6 were added at the indicated time (arrow). Reaction phases ix-xi correspond to that run only. For TOF regression plots, s. Fig. S81-S89† referring to reaction phases vii and viii-xi. ment (Fig. 11). Using only one equivalent of 5a, an approximately halved TOF for the same conversion interval (30-75\%) of $2.4 \pm 0.1 \mathrm{~h}^{-1}$ results. When three or more equivalents of $5 \mathrm{a}$ are added to $\left[(\mathbf{1 b})_{2}(\mathbf{A u})_{3}\right](\mathbf{O T f})_{3}$, the increment in TOF is by far greater than expected from the addition of one and two equivalents. When the reaction profiles obtained from adding four and six equivalents of $\mathbf{5 a}$ to $\left[(\mathbf{1 b})_{2}(\mathbf{A u})_{3}\right](\mathbf{O T f})_{3}$ are followed more closely by using smaller time intervals for the measurements (Fig. 13, top right), close-to-identical TOF for both cases result (shaded bars in Fig. 13, bottom). Relating these findings to the steric characterisation of the gold(I) centres by their respective buried volume (vide supra), it thus seems possible that the first two oxidations might be localised at the central ferrocenylene moieties ( $\mathrm{Fe}(1)$ and $\mathrm{Fe}(4))$, in turn activating the more buried central gold(I) ion $\mathrm{Au}(1)$. In the third and fourth oxidation, the chelated outer gold(I) centres $\mathrm{Au}(2)$ and $\mathrm{Au}(3)$, characterised by a higher substrate approachability, might followingly be activated, resulting in a sharp activity increase. In the absence of substrate, stepwise addition of up to six equivalents of $5 \mathbf{a}$ to $\left[(\mathbf{1 b})_{2}(\mathbf{A u})_{3}\right](\mathbf{O T f})_{3}$ resulted in a broadening and subsequent disappearance of the ferrocenylene and benzenecore signals in the corresponding ${ }^{1} \mathrm{H}$ NMR spectra, while the ${ }^{31} \mathrm{P}\left\{{ }^{1} \mathrm{H}\right\}$ NMR signals, next to being strongly broadened, became successively shifted to higher field (Fig. S98 and S99†). Upon addition of 6.6 eq. of $\mathbf{6}$, the original spectral features of $\left[(\mathbf{1 b})_{2}(\mathbf{A u})_{3}\right](\mathbf{O T f})_{3}$ were almost fully recovered with some delay. Since no significant changes between the addition of four and six equivalents of $\mathbf{5 a}$ are observed in the corresponding ${ }^{31} \mathrm{P}\left\{{ }^{1} \mathrm{H}\right\}$ NMR spectra, it is possible that the fourfold oxidation is the limit of the oxidation potential of $\mathbf{5 a}$ under these conditions.

Thus, 4.4 eq. of 6 were added to a final run of $\left[(\mathbf{1 b})_{2}(\mathbf{A u})_{3}\right](\mathbf{O T f})_{3}$ oxidised by 4 eq. of 5a (purple hollow diamonds in Fig. 13, top right), and a decrease of activity to $0.27 \pm 0.08 \mathrm{~h}^{-1}$ (phase xi) results after prolonged waiting ( $>6 \mathrm{~h}$ after addition of 6 ), mirroring the observations from SEC and NMR spectroscopy. Immediately after the addition of $\mathbf{6}$ (phase $\mathbf{x}$ ), the TOF is reduced to about a third $\left(14 \pm 1 \mathrm{~h}^{-1}\right)$ of the previous value $\left(41 \pm 1 \mathrm{~h}^{-1}\right)$.

While all catalytic activities are far from record-breaking, ${ }^{123}$ the highly oxidised forms of both $\left[(\mathbf{1 a})_{2}(\mathbf{A u})_{3}\right](\mathbf{O T f})_{3}$ and $\left[(\mathbf{1 b})_{2}(\mathbf{A u})_{3}\right](\mathbf{O T f})_{3}$ convert 2 faster than tris(chloridogold(I)) complexes of $\mathbf{1 a}-\mathbf{c}$ at the same gold(I) concentration. ${ }^{36}$

Their intriguing behaviour warrants a more detailed study on the corresponding oxidation/reduction mechanisms in RSC, and we are currently working on understanding the switching behaviour as well as investigating the use of $\mathbf{1 a - c}$ for different catalytic transformations.

\section{Conclusions}

$C_{3}$-Symmetric tris-phosphanes $\mathbf{1 a}-\mathbf{c}$ and a perfluorophenyl derivative of $1 \mathbf{a}, 1 \mathbf{a}^{\mathbf{F}}$, have been studied with respect to their coordination chemistry towards gold(I). Owing to steric strain arising from the clashing ortho substituents of the arene and 
the cyclopentadienyl rings, the tricoordinate bonding mode is reserved for the triazine derivative [1a(Au)]OTf, while $1: 1 \mathrm{com}$ plexes of $\mathbf{1 b}$ and $\mathbf{1 c}$ prefer a fluctional dicoordinate bonding mode. Steric strain can further be mitigated by adopting a $\mu_{3}: \kappa^{1} P, \kappa^{1} P^{\prime}, \kappa^{1} P^{\prime \prime}$ coordination mode, observed for 1c forming a one-dimensional coordination polymer with gold(I) in a $2: 3$ ligand-to-metal ratio. This very ratio can also be used to form discrete $2: 3$ complexes of $\mathbf{1 a}$ and $\mathbf{1 b}$ which, in contrast to the $1: 1$ complexes, show promising properties in the redoxswitchable ring-closing isomerisation of propargylic amide 2 including multi-state activity behaviour.

\section{Conflicts of interest}

There are no conflicts to declare.

\section{Acknowledgements}

Financial support by the Studienstiftung des deutschen Volkes (doctoral fellowships to P. C. and A. S.), the DFG (He 1376/ 51-1), and the Graduate School BuildMoNa is gratefully acknowledged. M. R. R. gratefully acknowledges funding provided by Universität Stuttgart, Stuttgart, Germany. The authors thank Dr Eckhard Bill (MPI CEC, Mülheim (Ruhr)) for supporting EPR and Mössbauer spectroscopy measurements, M. Sc. Nils Rotthowe and Prof. Rainer Winter (Universität Konstanz) for recording the room temperature-SEC spectra of $[\mathbf{1 b}(\mathbf{A u})] \mathbf{O T f}$, and M. Sc. Luis Dütsch and Prof. Manfred Scheer for the generous donation of $\mathbf{5 a}$.

\section{Notes and references}

1 Ferrocenes. Ligands, Materials and Biomolecules, ed. P. Štěpnička, J. Wiley, Chichester, England, Hoboken, NJ, 2008.

2 Ferrocenes. Homogeneous Catalysis, Organic Synthesis, Materials Science, ed. A. Togni and T. Hayashi, Wiley-VCH Verlag GmbH \& Co. KGaA, Weinheim, 1995.

3 R. Horikoshi, Coord. Chem. Rev., 2013, 257, 621.

4 D. Astruc, Eur. J. Inorg. Chem., 2017, 2017, 6.

5 P. Štěpnička, Eur. J. Inorg. Chem., 2017, 2017, 215.

6 Chiral Ferrocenes in Asymmetric Catalysis, ed. L.-X. Dai and X.-L. Hou, Wiley-VCH Verlag GmbH \& Co. KGaA, Weinheim, Germany, 2009.

7 R. Gómez Arrayás, J. Adrio and J. C. Carretero, Angew. Chem., Int. Ed., 2006, 45, 7674.

8 L.-X. Dai, T. Tu, S.-L. You, W.-P. Deng and X.-L. Hou, Acc. Chem. Res., 2003, 36, 659.

9 J. Wei and P. L. Diaconescu, Acc. Chem. Res., 2019, 52, 415.

10 A. J. Teator, D. N. Lastovickova and C. W. Bielawski, Chem. Rev., 2016, 116, 1969.

11 Y. Ryu, G. Ahumada and C. W. Bielawski, Chem. Commun., 2019, 55, 4451.
12 A. M. Allgeier, C. S. Slone, C. A. Mirkin, L. M. LiableSands, G. P. A. Yap and A. L. Rheingold, J. Am. Chem. Soc., 1997, 119, 550.

13 A. M. Allgeier and C. A. Mirkin, Angew. Chem., Int. Ed., 1998, 37, 894.

14 I. M. Lorkovic, R. R. Duff and M. S. Wrighton, J. Am. Chem. Soc., 1995, 117, 3617.

15 C. K. A. Gregson, V. C. Gibson, N. J. Long, E. L. Marshall, P. J. Oxford and A. J. P. White, J. Am. Chem. Soc., 2006, 128, 7410.

16 M. Sawamura, H. Hamashima and Y. Ito, Tetrahedron: Asymmetry, 1991, 2, 593.

17 M. Sawamura, A. Yamauchi, T. Takegawa and Y. Ito, J. Chem. Soc., Chem. Commun., 1991, 45, 874.

18 L. Hettmanczyk, L. Suntrup, S. Klenk, C. Hoyer and B. Sarkar, Chem. - Eur. J., 2017, 23, 576.

19 T.-Y. Dong, K. Chen, M.-C. Lin and L. Lee, Organometallics, 2005, 24, 4198.

20 W. Chen, P. J. McCormack, K. Mohammed, W. Mbafor, S. M. Roberts and J. Whittall, Angew. Chem., Int. Ed., 2007, 46, 4141.

21 S. Santi, A. Bisello, R. Cardena and A. Donoli, Dalton Trans., 2015, 44, 5234.

22 A. Donoli, A. Bisello, R. Cardena, C. Prinzivalli and S. Santi, Organometallics, 2013, 32, 1029.

23 Y.-K. Lim, S. Wallace, J. C. Bollinger, X. Chen and D. Lee, Inorg. Chem., 2007, 46, 1694.

24 M. S. Inkpen, S. Scheerer, M. Linseis, A. J. P. White, R. F. Winter, T. Albrecht and N. J. Long, Nat. Chem., 2016, 8,825 .

25 L. Xu, Y.-X. Wang, L.-J. Chen and H.-B. Yang, Chem. Soc. Rev., 2015, 44, 2148.

26 Y. Yu, A. D. Bond, P. W. Leonard, U. J. Lorenz, T. V. Timofeeva, K. P. C. Vollhardt, G. D. Whitener and A. A. Yakovenko, Chem. Commun., 2006, 2572.

27 A. Kasprzak, A. Kowalczyk, A. Jagielska, B. Wagner, A. M. Nowicka and H. Sakurai, Dalton Trans., 2020, 49, 9965-9971.

28 D. Astruc, C. Ornelas and J. Ruiz, Acc. Chem. Res., 2008, 41, 841.

29 A. K. Diallo, C. Absalon, J. Ruiz and D. Astruc, J. Am. Chem. Soc., 2011, 133, 629.

30 D. Astruc, J. Leather Sci. Eng., 2020, 2, 3534.

31 C. Dengiz, B. Breiten, J.-P. Gisselbrecht, C. Boudon, N. Trapp, W. B. Schweizer and F. Diederich, J. Org. Chem., 2015, 80, 882.

32 P. Neumann, H. Dib, A.-M. Caminade and E. Hey-Hawkins, Angew. Chem., Int. Ed., 2015, 54, 311.

33 P. Neumann, H. Dib, A. Sournia-Saquet, T. Grell, M. Handke, A.-M. Caminade and E. Hey-Hawkins, Chem. Eur. J., 2015, 21, 6590.

34 J. Popp, A.-M. Caminade and E. Hey-Hawkins, Eur. J. Inorg. Chem., 2020, 17, 1654.

35 A. Straube, P. Coburger, M. R. Ringenberg and E. Hey-Hawkins, Chem. - Eur. J., 2020, 26, 5758. 
36 A. Straube, P. Coburger, L. Dütsch and E. Hey-Hawkins, Chem. Sci., 2020, 11, 10657-10668.

37 U. Pfaff, A. Hildebrandt, D. Schaarschmidt, T. Hahn, S. Liebing, J. Kortus and H. Lang, Organometallics, 2012, 31, 6761 .

38 A. Preuß, M. Korb, D. Miesel, T. Rüffer, A. Hildebrandt and H. Lang, Dalton Trans., 2019, 48, 14418.

39 R. K. Al-Shewiki, M. Korb, A. Hildebrandt, S. Zahn, S. Naumov, R. Buschbeck, T. Rüffer and H. Lang, Dalton Trans., 2019, 48, 1578.

40 S. Santi, L. Orian, A. Donoli, A. Bisello, M. Scapinello, F. Benetollo, P. Ganis and A. Ceccon, Angew. Chem., Int. Ed., 2008, 47, 5331.

41 S. Rossi, A. Bisello, R. Cardena, L. Orian and S. Santi, Eur. J. Org. Chem., 2017, 5966.

42 S. Rossi, A. Bisello, R. Cardena and S. Santi, Organometallics, 2018, 37, 4242.

43 S. Steffens, M. H. Prosenc, J. Heck, I. Asselberghs and K. Clays, Eur. J. Inorg. Chem., 2008, 1999.

44 J. M. Speck, M. Korb, A. Schade, S. Spange and H. Lang, Organometallics, 2015, 34, 3788.

45 A. Hildebrandt, D. Schaarschmidt and H. Lang, Organometallics, 2011, 30, 556.

46 M. Korb, U. Pfaff, A. Hildebrandt, T. Rüffer and H. Lang, Eur. J. Inorg. Chem., 2014, 2014, 1051.

47 A. Hildebrandt and H. Lang, Dalton Trans., 2011, 40, 11831.

48 D. Miesel, A. Hildebrandt and H. Lang, Curr. Opin. Electrochem., 2018, 8, 39.

49 G. Filipczyk, S. W. Lehrich, A. Hildebrandt, T. Rüffer, D. Schaarschmidt, M. Korb and H. Lang, Eur. J. Inorg. Chem., 2017, 2017, 263.

50 I. Caracelli, J. Zukerman-Schpector and E. R. T. Tiekink, Gold Bull., 2013, 46, 81.

51 A. S. K. Hashmi, J. P. Weyrauch, W. Frey and J. W. Bats, Org. Lett., 2004, 6, 4391.

52 A. M. Wright, B. J. Irving, G. Wu, A. J. H. M. Meijer and T. W. Hayton, Angew. Chem., Int. Ed., 2015, 54, 3088.

53 R. T. Stibrany, C. Zhang, T. J. Emge, H. J. Schugar, J. A. Potenza and S. Knapp, Inorg. Chem., 2006, 45, 9713.

54 C. Fan, C. Ma, C. Chen, F. Chen and Q. Liu, Inorg. Chem. Commun., 2003, 6, 491.

55 V. Lavallo, G. D. Frey, S. Kousar, B. Donnadieu and G. Bertrand, Proc. Natl. Acad. Sci. U. S. A., 2007, 104, 13569.

56 Q.-S. Li, C.-Q. Wan, R.-Y. Zou, F.-B. Xu, H.-B. Song, X.-J. Wan and Z.-Z. Zhang, Inorg. Chem., 2006, 45, 1888.

57 E. Herrero-Gómez, C. Nieto-Oberhuber, S. López, J. Benet-Buchholz and A. M. Echavarren, Angew. Chem., Int. Ed., 2006, 45, 5455.

58 P. Pérez-Galán, N. Delpont, E. Herrero-Gómez, F. Maseras and A. M. Echavarren, Chem. - Eur. J., 2010, 16, 5324.

59 Q.-L. Ni, X.-F. Jiang, T.-H. Huang, X.-J. Wang, L.-C. Gui and K.-G. Yang, Organometallics, 2012, 31, 2343.

60 C. Griebel, D. D. Hodges, B. R. Yager, F. L. Liu, W. Zhou, K. J. Makaravage, Y. Zhu, S. G. Norman, R. Lan, C. S. Day and A. C. Jones, Organometallics, 2020, 39(14), 2665-2671.
61 E. R. T. Tiekink and J. Zukerman-Schpector, CrystEngComm, 2009, 11, 1176.

62 M. A. Cinellu, M. Arca, F. Ortu, S. Stoccoro, A. Zucca, A. Pintus and L. Maiore, Eur. J. Inorg. Chem., 2019, 2019, 4784 .

63 S. Handa and L. M. Slaughter, Angew. Chem., Int. Ed., 2012, 51, 2912.

64 M. R. Holmes, J. F. Manganaro, C. L. Barnes and B. W. Gung, J. Organomet. Chem., 2015, 795, 18.

65 H. Teller, S. Flügge, R. Goddard and A. Fürstner, Angew. Chem., Int. Ed., 2010, 49, 1949.

66 C. R. Wade and F. P. Gabbaï, Angew. Chem., Int. Ed., 2011, 50, 7369.

67 E. J. Derrah, C. Martin, S. Ladeira, K. Miqueu, G. Bouhadir and D. Bourissou, Dalton Trans., 2012, 41, 14274.

68 V. Rampazzi, J. Roger, R. Amardeil, M.-J. Penouilh, P. Richard, P. Fleurat-Lessard and J.-C. Hierso, Inorg. Chem., 2016, 55, 10907.

69 U. Siemeling, T. Klemann, C. Bruhn, J. Schulz and P. Štěpnička, Z. Anorg. Allg. Chem., 2011, 637, 1824.

70 B. E. Cowie and D. J. H. Emslie, Organometallics, 2018, 37, 1007.

71 A. Bayler, A. Schier, G. A. Bowmaker and H. Schmidbaur, J. Am. Chem. Soc., 1996, 118, 7006.

72 E. M. Barranco, O. Crespo, M. C. Gimeno, A. Laguna, P. G. Jones and B. Ahrens, Inorg. Chem., 2000, 39, 680.

73 K. Škoch, I. Císařová and P. Štěpnička, Chem. - Eur. J., 2015, 21, 15998.

74 S. Alvarez, Dalton Trans., 2013, 42, 8617.

75 R. Horikoshi, T. Tominaga and T. Mochida, Cryst. Growth Des., 2018, 18, 5089.

76 L. A. Wilkinson, T. T. C. Yue, E. Massey, A. J. P. White and N. J. Long, Dalton Trans., 2018, 48, 72.

77 R. Horikoshi and T. Mochida, Eur. J. Inorg. Chem., 2010, 2010, 5355.

78 R. Shekurov, M. Khrizanforov, T. Gerasimova, Z. Yamaleeva, K. Ivshin, A. Lakomkina, I. Bezkishko, A. Kononov, O. Sinyashin, Y. Budnikova, O. Kataeva and V. Miluykov, Molecules, 2020, 25, 939.

79 V. Khrizanforova, R. Shekurov, V. Miluykov, M. Khrizanforov, V. Bon, S. Kaskel, A. Gubaidullin, O. Sinyashin and Y. Budnikova, Dalton Trans., 2020, 49, 2794.

80 S. L. James, Chem. Soc. Rev., 2009, 38, 1744.

81 M. Streitberger, A. Schmied and E. Hey-Hawkins, Inorg. Chem., 2014, 53, 6794.

82 R. Hoy, P. Lönnecke and E. Hey-Hawkins, Dalton Trans., 2018, 47, 14515.

83 R. J. Puddephatt, Coord. Chem. Rev., 2001, 216-217, 313.

84 J. Su, L. Yao, J. Zhang, S. Yuan, F. Xie, Y. Ding, M. Zhao, S. Wang, H. Li, S. Zhang, J. Wu and Y. Tian, New J. Chem., 2016, 40, 97.

85 C. L. Pollock, G. C. Saunders, E. C. M. S. Smyth and V. I. Sorokin, J. Fluor. Chem., 2008, 129, 142.

86 B. G. Anderson and J. L. Spencer, Chem. - Eur. J., 2014, 20, 6421. 
87 P. H. Lee, S. Kim, A. Park, B. C. Chary and S. Kim, Angew. Chem., Int. Ed., 2010, 49, 6806.

88 C. Shu, L. Li, C.-B. Chen, H.-C. Shen and L.-W. Ye, Chem. Asian J., 2014, 9, 1525.

89 J. Schießl, J. Schulmeister, A. Doppiu, E. Wörner, M. Rudolph, R. Karch and A. S. K. Hashmi, Adv. Synth. Catal., 2018, 360, 2493.

90 S.-H. Shin, Bull. Korean Chem. Soc., 2005, 26, 1925.

91 Y. H. Lee and B. Morandi, Angew. Chem., Int. Ed., 2019, 58, 6444.

92 Y. Yang, L. Eberle, F. F. Mulks, J. F. Wunsch, M. Zimmer, F. Rominger, M. Rudolph and A. S. K. Hashmi, J. Am. Chem. Soc., 2019, 141, 17414.

93 M. Nishikawa, Y. Wakita, T. Nishi, T. Miura and T. Tsubomura, Dalton Trans., 2015, 44, 9170.

94 Y. Ren, Y. Dienes, S. Hettel, M. Parvez, B. Hoge and T. Baumgartner, Organometallics, 2009, 28, 734.

95 Y. Ren, A. Orthaber, R. Pietschnig and T. Baumgartner, Dalton Trans., 2013, 42, 5314.

96 O. V. Gusev, T. Y. A. Peganova, A. M. Kalsin, N. V. Vologdin, P. V. Petrovskii, K. A. Lyssenko, A. V. Tsvetkov and I. P. Beletskaya, Organometallics, 2006, 25, 2750.

97 A. M. Kalsin, N. V. Vologdin, T. A. Peganova, P. V. Petrovskii, K. A. Lyssenko, F. M. Dolgushin and O. V. Gusev, J. Organomet. Chem., 2006, 691, 921.

98 O. V. Gusev, M. G. Peterleitner, A. M. Kal'sin and N. V. Vologdin, Russ. J. Electrochem., 2003, 39, 1293.

99 N. J. Adamson, H. Jeddi and S. J. Malcolmson, J. Am. Chem. Soc., 2019, 141, 8574.

100 Please note that ${ }^{19} \mathrm{~F}\left\{{ }^{1} \mathrm{H}\right\}$ NMR chemical shifts for VII have been reported with reference to $\delta\left(\mathrm{CF}_{3} \mathrm{COOH}\right)=0 \mathrm{ppm}$, while chemical shifts reported in this publication follow the IUPAC convention of $\delta\left(\mathrm{CFCl}_{3}\right)=0 \mathrm{ppm}$, resulting in $\Delta \delta=-76.6 \mathrm{ppm}$.

101 H. W. Chen and E. R. T. Tiekink, Acta Crystallogr., Sect. E: Struct. Rep. Online, 2003, 59, m50-m52.

102 Y. Dienes, U. Englert and T. Baumgartner, Z. Anorg. Allg. Chem., 2009, 635, 238.

103 G. Moreno-Alcántar, H. Hernández-Toledo, J. M. GuevaraVela, T. Rocha-Rinza, Á. Martín Pendás, M. Flores-Álamo and H. Torrens, Eur. J. Inorg. Chem., 2018, 2018, 4413.

104 B. Cordero, V. Gómez, A. E. Platero-Prats, M. Revés, J. Echeverría, E. Cremades, F. Barragán and S. Alvarez, Dalton Trans., 2008, 2832.

105 M. Streitberger, A. Schmied, R. Hoy and E. Hey-Hawkins, Dalton Trans., 2016, 45, 11644.

106 A. Schulz, A. Villinger and A. Westenkirchner, Inorg. Chem., 2014, 53, 3183.

107 W. Schuh, H. Kopacka, K. Wurst and P. Peringer, Chem. Commun., 2001, 2186.

108 C. Hollatz, A. Schier and H. Schmidbaur, Inorg. Chem. Commun., 1998, 1, 115.

109 D. Li, C.-M. Che, S.-M. Peng, S.-T. Liu, Z.-Y. Zhou and T. C. W. Mak, J. Chem. Soc., Dalton Trans., 1993, 189.

110 G. S. M. Tong, S. C. F. Kui, H.-Y. Chao, N. Zhu and C.-M. Che, Chem. - Eur. J., 2009, 15, 10777.
111 P. Sevillano, M. E. García, A. Habtemariam, S. Parsons and P. J. Sadler, Met.-Based Drugs, 1999, 6, 211.

112 F. H. Allen, Acta Crystallogr., Sect. B: Struct. Sci., 2002, 58, 380.

113 M. J. Verschoor-Kirss, O. Hendricks, C. M. Verschoor, R. Conry and R. U. Kirss, Inorg. Chim. Acta, 2016, 450, 30 .

114 A. Louati, M. Gross, L. Douce and D. Matt, J. Organomet. Chem., 1992, 438, 167.

115 K. D. Reichl, D. H. Ess and A. T. Radosevich, J. Am. Chem. Soc., 2013, 135, 9354.

116 F. Barrière, R. U. Kirss and W. E. Geiger, Organometallics, 2005, 24, 48.

117 H. Baumgärtel, Electrochemistry. A Guide for Newcomers, De Gruyter, Berlin/Boston, 2019.

118 M. V. Mirkin, Determination of Electrode Kinetics in Handbook of Electrochemistry, ed. C. G. Zoski, Elsevier, Oxford, 2007, pp. 639-660.

119 M. Iyoda, T. Kondo, T. Okabe, H. Matsuyama, S. Sasaki and Y. Kuwatani, Chem. Lett., 1997, 26, 35.

120 F. Barrière and W. E. Geiger, J. Am. Chem. Soc., 2006, 128, 3980.

121 A. G. Furneaux, N. A. Piro, R. Hernández Sánchez, K. M. Gramigna, N. Fey, M. J. Robinson, W. S. Kassel and C. Nataro, Dalton Trans., 2016, 45, 4819.

122 D. A. Durfey, R. U. Kirss, C. Frommen and W. Feighery, Inorg. Chem., 2000, 39, 3506.

123 S. Vanicek, M. Podewitz, J. Stubbe, D. Schulze, H. Kopacka, K. Wurst, T. Müller, P. Lippmann, S. Haslinger, H. Schottenberger, K. R. Liedl, I. Ott, B. Sarkar and B. Bildstein, Chem. - Eur. J., 2018, 24, 3742 .

124 S. Klenk, S. Rupf, L. Suntrup, M. van der Meer and B. Sarkar, Organometallics, 2017, 36, 2026.

125 L. Hettmanczyk, D. Schulze, L. Suntrup and B. Sarkar, Organometallics, 2016, 35, 3828.

126 P. Veit, C. Volkert, C. Förster, V. Ksenofontov, S. Schlicher, M. Bauer and K. Heinze, Chem. Commun., 2019, 55, 4615.

127 M. Rigo, L. Hettmanczyk, F. J. L. Heutz, S. Hohloch, M. Lutz, B. Sarkar and C. Müller, Dalton Trans., 2016, 46, 86.

128 S. Díez-González and S. P. Nolan, Coord. Chem. Rev., 2007, 251, 874.

129 A. Poater, F. Ragone, S. Giudice, C. Costabile, R. Dorta, S. P. Nolan and L. Cavallo, Organometallics, 2008, 27, 2679.

130 L. Falivene, Z. Cao, A. Petta, L. Serra, A. Poater, R. Oliva, V. Scarano and L. Cavallo, Nat. Chem., 2019, 11, 872.

131 I. Krossing, Chem. - Eur. J., 2001, 7, 490.

132 I. M. Riddlestone, A. Kraft, J. Schaefer and I. Krossing, Angew. Chem., Int. Ed., 2018, 57, 13982.

133 A. Feyrer, M. K. Armbruster, K. Fink and F. Breher, Chem. - Eur. J., 2017, 23, 7402.

134 It should be noted that, while the TOF is an oversimplified approximation of catalytic activity, trying to fit the reaction profiles by first- or second-order kinetics through 
the respective curve transformation did not yield meaningful profiles for the corresponding linear fits.

135 H. B. Gray, Y. S. Sohn and N. Hendrickson, J. Am. Chem. Soc., 1971, 93, 3603.

136 D. M. Duggan and D. N. Hendrickson, Inorg. Chem., 1975, 14, 955 .
137 S. Hartmann, R. F. Winter, B. M. Brunner, B. Sarkar, A. Knödler and I. Hartenbach, Eur. J. Inorg. Chem., 2003, 2003, 876.

138 D. Zuccaccia, A. Del Zotto and W. Baratta, Coord. Chem. Rev., 2019, 396, 103.

139 A. Zhdanko and M. E. Maier, ACS Catal., 2014, 4, 2770. 